\title{
Analysis of The Tool-Chip Interface Temperature In Cryogenic Hard Turning of Aisi D6 Tool Steel
}

\section{Edmilson Dantas de Lima Jr}

Federal Institute of Education

Anderson Clayton Alves De Melo ( $\boldsymbol{\nabla}$ anderson.melo@ufm.br)

Federal University of Rio Grande do Norte: Universidade Federal do Rio Grande do Norte

https://orcid.org/0000-0001-5679-3562

\section{Adilson José de Oliveira}

Federal University of Rio Grande do Norte

Júlio César Giubilei Milan

Santa Catarina State University

Álisson Rocha Machado

Federal University of Uberlandia

\section{Research Article}

Keywords: Hard turning, Tool-chip interface temperature, Hardened AISI D6 tool steel, Cryogenic machining, Tool-workpiece thermocouple method

Posted Date: August 4th, 2021

DOl: https://doi.org/10.21203/rs.3.rs-741375/v1

License: (c) (1) This work is licensed under a Creative Commons Attribution 4.0 International License.

Read Full License 


\title{
ANALYSIS OF THE TOOL-CHIP INTERFACE TEMPERATURE IN CRYOGENIC HARD TURNING OF AISI D6 TOOL STEEL
}

\section{${ }^{1}$ Edmilson Dantas de Lima Júnior, ${ }^{2,}{ }^{\star}$ Anderson Clayton Alves de Melo, ${ }^{2}$ Adilson José de Oliveira, Júlio César Giubilei Milan ${ }^{3}$, Álisson Rocha Machado ${ }^{4,5}$}

${ }^{1}$ Federal Institute of Education, Science and Technology of Rio Grande do Norte, 160 BR-101, S/N - Areia Branca, Canguaretama/RN, Brazil, Zip code. 59.190-000

${ }^{2}$ Federal University of Rio Grande do Norte, Senador Salgado Filho Avenue, 3000 - Lagoa Nova, Natal/RN, Brazil, Zip code. 59.078-970

${ }^{3}$ Santa Catarina State University, Paulo Malschitzki Street, 200 - Zona Industrial Norte, Joinville/SC, Brazil, Zip code. 89.219-710

${ }^{4}$ Mechanical Engineering Graduate Program, Pontifícia Universidade Católica do Paraná - PUCPR, CEP 80215-901, Curitiba, PR, Brasil

${ }^{5}$ Federal University of Uberlandia, School of Mechanical Engineering, Av. João Naves de Ávila, 2121, Bloco 1M, 38400-902, Uberlândia, MG, Brasil.

\begin{abstract}
Hard turning is considered a strong candidate to partially replace grinding in finishing operations. However, as in the grinding operation, hard turning produces high temperatures that contributes to accelerate the cutting tool wear. In order to minimize this effect, cutting fluids can be applied as an alternative, even when PCBN inserts are used as cutting tools. However, there are many drawbacks associated with the use of cutting fluids, particularly those of mineral base, as they are hazardous to the environment. In this context, the need for more eco-friendly cutting fluids is growing and liquid nitrogen $\left(\mathrm{LN}_{2}\right)$ offers a promising alternative. Previous studies have shown that $\mathrm{LN}_{2}$ can significantly reduce the cutting tool wear rate in comparison with other cooling strategies, and this is normally attributed to a reduction in the tool-chip interface temperature. However, investigations on the tool-chip interface temperature in cryogenic machining are scarce in the literature, particularly with regard to the turning of tool steels, and this study was performed to partially fill this gap. The toolchip interface temperature during the turning of quenched and tempered AISI D6 tool steel, under dry conditions and using $\mathrm{LN}_{2}$, was investigated. A tool-workpiece thermocouple system was developed for this purpose and calibrated using a data acquisition system based on the low-cost Arduino Uno platform. In the turning tests, liquid nitrogen was delivered at the tool flank face of PCBN inserts at three cutting speeds with a constant feed rate and depth of cut. The results showed that $\mathrm{LN}_{2}$ was effective in reducing the tool-chip interface temperature at the lowest cutting speed; however, when this cutting parameter was increased, the reduction in the interface temperature was minimal as compared with the dry condition.
\end{abstract}

Keywords: Hard turning, Tool-chip interface temperature, Hardened AISI D6 tool steel, Cryogenic machining, Tool-workpiece thermocouple method.

* Corresponding author. Tel.: +55 8499629 3999; E-mail: anderson.melo@ufrn.br 


\section{INTRODUCTION}

Because of its relative low cost and flexibility, hard turning has been proposed to partially replace the grinding operation in the manufacturing of hardened steel parts with high accuracy and surface quality [1]. According to Sharma et al. [2], when compared with grinding, hard turning presents several advantages, such as reduced set-up and manufacturing times, use of single point cutting edge and only one clamp, and more effective cutting time. Additionally, hard turning produces a machined surface with longer rolling contact fatigue life as compared to a ground surface, with the same or even lower average surface roughness [3]. This is mainly because it produces a deep layer with compressive residual stresses at the workpiece surface, whereas grinding can induce tensile residual stresses, as noted by Guo and Yen [4] and Matsumoto et al. [5]. In addition to these technical advantages, hard turning is less environmentally harmful than grinding if the operation is performed under dry conditions, i.e., without the assistance of a lubri-cooling medium. In this case, the process can be considered as eco-friendly, because there is no residue from cutting fluids, which are usually mineral-based emulsions that are extremely harmful to the environment and human health, besides being costly [6]. As a result, additional inputs and processes have to be introduced into the production line, increasing the production cost per part. Additionally, in this context, there is increasing pressure from governmental and non-governmental entities for industries to adopt cleaner production technologies [7]. In the case of grinding, dry machining is not a suitable option because of the extremely high amount of thermal energy generated during the process, which can damage the workpiece surface integrity. Although dry hard turning presents many advantages over grinding, it also leads to high cutting temperatures, which promote thermally-induced wear mechanisms at the cutting edge, such as diffusion and oxidation, leaving the tool more prone to adhesion and abrasion and reducing the cutting tool life [8]. Thus, in the search for improved methods of machining hardened steel components, the contemporary context of sustainability needs to be considered, seeking solutions that address technical, economic, environmental and health issues. In this regard, an alternative that has been extensively investigated in recent years is $\mathrm{LN}_{2}$-assisted machining.

Several previous investigations have shown the many benefits of using $L_{2}$ as a cutting fluid in the turning of hardened steels instead of dry or conventional flood machining. In most cases these benefits are presented in terms of increased cutting tool life, and consequently decreased tool wear rate, increased workpiece surface hardness and surface compressive residual stresses, and improved surface roughness [9-13].

Biček et al. [13] machined quenched and tempered AISI 52100 bearing steels bars, with hardness of $850 \mathrm{HV}\left(\sim 64 \mathrm{HRc}\right.$ ) under cryogenic (with $\mathrm{LN}_{2}$ ) and dry conditions for comparison. They reported that, in contrast to dry cutting, $\mathrm{LN}_{2}$-assisted turning did not produce the fragile white layer beneath the workpiece surface, partially due to lower cutting temperatures provided by the liquid nitrogen. Additionally, there was a $15 \%$ increase in the volume of material removed from the workpiece under cryogenic conditions in comparison with dry machining. Residual stresses were also measured on the machined surface in the hoop and axial directions at different depths beneath the workpiece surface. The authors noted a behavior typical for conventional dry machining regardless of the measurement direction, i.e., the compressive stresses were relatively low on the surface and increased in the first few micrometers beneath the surface, due to the induction of thermal stress at the beginning of the heat-affected zone. After reaching the end of the heat-affected zone, the mechanical stress starts to 
reduce the compressive stress. In contrast, in cryogenic machining, the thermal stress is considerably reduced and thus the compressive stress on the surface and just beneath it increases. Thereafter, the behavior is similar to that for conventional dry machining. This result is beneficial for components that are submitted to rolling contact fatigue, as in the case of bearings.

Shokrani et al. [12] published a comprehensive review of recent advances in the area of cryogenic cryogenic machining and processing. They highlighted the effects of cryogenic cooling on the workpiece behavior during machining and on the machinability output parameters, such as tool life, cutting temperature and surface integrity, for various tool-workpiece pairs. With regard to hard-to-cut materials, such as hardened steels, they noted that high temperatures are generated in the cutting zone, affecting the tool life, surface finish and geometrical accuracy of the machined part. In this situation, cooling the cutting zone with a cryogenic fluid not only cools the cutting zone but can also change the workpiece and cutting tool material properties, which can improve the machining process performance. The hardness, modulus of elasticity, strength and brittleness are generally increased in the case of cryogenic machining, which benefits the machinability by reducing the cutting forces and the tendency for the formation of a built-up edge, and the chip breakability is enhanced. Nevertheless, the cited authors warned that the benefits of cryogenic cooling do not apply to all materials. With regard to the tribological behavior of materials at cryogenic temperatures, Shokrani and colleagues [12] reported that a cryogenic temperature is generally expected to change the tribological behavior of the sliding surfaces by increasing the surface hardness and reducing the interface temperature. This reduces the friction coefficient, although there are exceptions depending on the types of materials that are in contact. Additionally, the authors cited the work of Hong et al. [14], who investigated the effects of spraying $\mathrm{LN}_{2}$ between sliding surfaces, with the formation of a liquid/gas film between them, reducing the contact area and friction forces. They also observed a reduction in the interfacial temperature, which modifies the sliding surfaces due to reduced chemical reactivity and welding tendency, increasing the surface hardness of the sliding materials and reducing the tendency for the coefficient of friction to be increased over time.

Hong and Ding [15] investigated the efficiency of five methods of cryogenic turning assisted by liquid nitrogen in the machining of Ti-6Al-4V alloy, i.e., delivering $\mathrm{LN}_{2}$ at the rake face, flank face, or at both faces close to the main cutting edge, precooling the workpiece, and cooling the bottom of the tool. For comparison, they also performed turning trials under dry conditions and applying a conventional flood emulsion. The cutting temperatures were theoretically estimated using the finite element method (FEM), considering heat transfer and two-dimensional numerical modeling approaches. These were experimentally validated using a K-type thermocouple embedded in a carbide insert. All numerical computational models considered a depth of cut of $1.27 \mathrm{~mm}$, a feed rate of $0.254 \mathrm{~mm} / \mathrm{rev}$ and cutting speeds of $60,90,120$, and $150 \mathrm{~m} / \mathrm{min}$. It was concluded that applying $\mathrm{LN}_{2}$ on the rake and flank faces simultaneously provided the lowest temperature at the tool-chip interface, reducing it to less than $500^{\circ} \mathrm{C}$, even at the highest cutting speed. According to the authors, under cryogenic cooling the diffusivity of titanium into the cutting tool material, a mechanism that is considered to be mainly responsible for tool wear when machining Ti6-Al4-V alloy, becomes negligible. In this case, a cutting speed twice that used under conventional emulsion machining (usually limited to $60 \mathrm{~m} / \mathrm{min}$ ) could be used while maintaining an acceptable tool life. It was also noted that the performance of the cryogenic cooling method is dependent on the cutting speed, i.e., at lower cutting speeds with $\mathrm{LN}_{2}$ applied either at the flank or at the rake face the process is competitive with emulsion cooling in terms of reducing the cutting temperature. 
Dhar et al. [16] performed an investigation similar to that of Hong and Ding [15]. They studied the influence of $\mathrm{LN}_{2}$ on the tool-chip interface temperature when turning AISI 1040 plain carbon steel with two types of cemented carbide inserts (SNMG 120408-26 TTS and SNMM 120408 TTS, manufactured by WIDIA). Dry turning tests were also performed for comparison. As in the case of Hong and Ding [15], they also used a two-dimensional finite element model to estimate the temperature distribution in the cutting tool, chip and workpiece. The experimental method used to obtain the tool-chip interface temperatures was the tool-workpiece thermocouple technique. Experiments were performed varying the feed rate $(0.12,0.16,0.20$ and $0.24 \mathrm{~mm} / \mathrm{rev})$ and the cutting speed $(66,85,110$ and $144 \mathrm{~m} / \mathrm{min}$ ), keeping the depth of cut constant and equal to $1.5 \mathrm{~mm}$. On analyzing the distribution of temperatures obtained through the finite element model, it was noted that the maximum temperature occurred at around the middle of the tool-chip contact length regardless of the cutting strategy (dry or $\mathrm{LN}_{2}$ ), as also observed by Hong and Ding [15] when turning Ti-6AI-4V alloy. It was also noted that the application of liquid nitrogen substantially reduced the maximum temperature at the tool-chip interface and the wear land for both inserts, besides making the chips curl more than under dry cutting, reducing the tool-chip contact length. The researchers also concluded that the low cutting temperatures under cryogenic cooling can be attributed to the reduced tool-chip contact length under this condition, which diminishes the cutting forces, and also improved heat transfer, due to the extremely low temperatures provided by the liquid nitrogen. Finally, it was noted that the benefits of cryogenic cooling were enhanced at lower cutting speeds, when a large portion of the tool-chip contact area remains elastic in nature, promoting a more effective penetration of the liquid nitrogen.

Based on reports published on the subject addressed herein, it can be noted that there is a consensus among researchers that $\mathrm{LN}_{2}$-assisted machining is able to reduce the cutting temperature, even at the tool-chip interface, increasing the cutting tool life and improving the surface integrity in many cases. However, studies involving the measurement of cutting temperatures during the cryogenic turning of hardened tool steels are scarce. Thus, aiming to fill this gap, in this study the toolchip interface temperatures when turning quenched and tempered AISI D6 steel were determined using a tool-workpiece thermocouple system that was developed based on research by Kaminise et al. [17], which will be described in the next section.

\subsection{Tool-workpiece thermocouple technique}

According to Shaw [18], the tool-workpiece thermocouple technique was developed almost simultaneously in the 1920 s by Shore in the United States, Gottwein in Germany and Herbert in Great Britain. It is used to determine the average tool-chip interface temperature and is based on the fact that an electromotive force (EMF) is generated at the interface of two dissimilar metals when the temperature of the interface changes, as in the case of the contact between workpiece and cutting tool during turning procedures.

The laws of thermoelectric circuits applicable to the tool-workpiece thermocouple technique are [18]:

1. The EMF in a thermoelectric circuit is solely dependent on the difference between the temperatures of the hot and cold junctions and it is independent of the gradients in the parts making up the system. 
2. The EMF generated is independent of the size and resistance of the conductors.

3. When the junction of two metals is at uniform temperature, the EMF generated is not affected if a third metal, which is at the same temperature, is used to make the junction between the first two.

In practice, the application of these principles in turning process can be explained by analyzing Fig. 1. The tool-chip contact forms the hot junction "H", while the points "A" and "B" constitute the cold junctions, which remain at room temperature. Mercury is normally used to establish electrical contact with the rotating shaft, allowing the closing of the circuit, although Santos Jr. et al. [19] have successfully used pure aluminum and bronze pins to establish the electrical contact with the rotating workpiece in turning. The use of pin brushes is advantageous since mercury is toxic and also high cutting conditions can be used because they do not interfere in the system rigidity, as shown by Santos Jr et al. [20] in turning aluminum alloys. The connection wires "C" and "D" can be made of simple copper wires, which must be kept at the same temperature in order to prevent an unwanted signal. It is important to mention that the mercury can be placed inside a modified live center in the tailstock, as in this investigation.

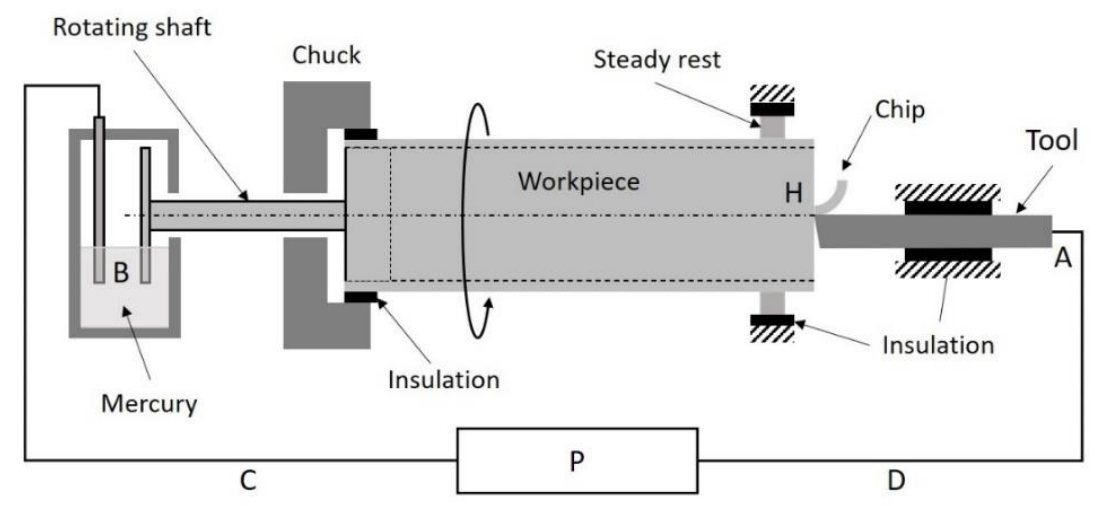

Figure 1. Tool-workpiece thermocouple technique. Adapted from Shaw [18].

To transform the electrical signal into temperature, an appropriate method of calibration is needed. Shaw [18] presented the arrangement shown in Fig. 2 as the simplest and most accurate approach to calibration in the tool-workpiece thermocouple technique.

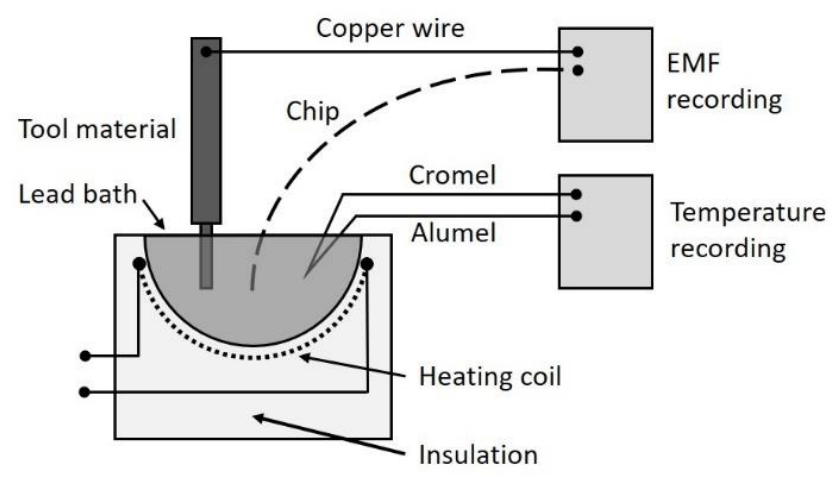

Figure 2. Arrangement for calibration in the tool-workpiece thermocouple technique. Adapted from Shaw [18]. 
Also, according to Shaw [18], the most convenient form of workpiece for calibration is a long chip produced by continuous cutting. The end of the tool is best ground to a 1/8" ( 3 mm) diameter, both to ensure uniform temperature and to limit the amount of heat transferred to the "cold" end of the tool. To keep the "cold" end at room temperature, it is advisable to use a long tool, otherwise corrections may be necessary. If the workpiece does not form long chips, a pin similar to the tool needs to be prepared. As long as the lead bath is at uniform temperature, its presence will have no effect on the EMF measured, according to the third law of thermoelectricity. Its temperature is measured with a standard chromel-alumel thermocouple.

It should be noted that the tool-workpiece thermocouple technique provides the mean temperature, considering both the tool-chip contact area (at the rake face) and the tool-workpiece contact area (at the flank face). However, it is common to refer to the temperature obtained through this method simply as the tool-chip interface temperature, mainly when using a fresh cutting edge.

Analysis of the thermoelectric circuit is fundamental to correctly understanding the relationship between the EMFs generated and the temperature, and to determine how the circuit junctions can influence the resulting EMF [19].

In a circuit composed of two different metallic materials ( $A$ and $B$ ) with their junctions at temperatures $T_{1}$ and $T_{2}$, respectively, and with $T_{1} \neq T_{2}$, an EMF ( $\left.E_{R}\right)$ appears (see Fig. 3), and its value is the sum of the voltages at thermojunctions 1 and 2 (Eq. 1).

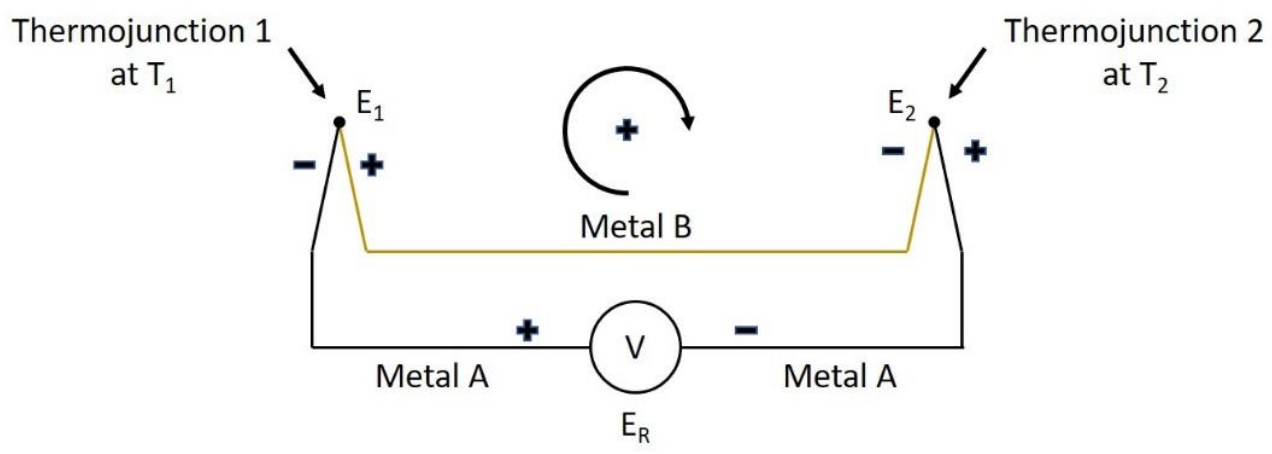

Figure 3. Basic thermoelectric circuit.

$\mathrm{E}_{\mathrm{R}}=\mathrm{E}_{1}+\mathrm{E}_{2}$

Voltages E1 and E2 are dependent on the temperature and the Seebeck coefficient $(\sigma)$. This coefficient represents the voltage variation with the temperature, which is dependent on the nature of the thermocouple materials. In practice, this relation is generally constant, resulting in a linear function, as shown by Eq. 2 .

$E_{R}=\sigma_{A B} T_{1}+\sigma_{B A} T_{2}$

where $\sigma_{A B}$ and $\sigma_{B A}$ represent the Seebeck coefficients at thermojunctions 1 and 2, respectively. It is important to note that $\sigma_{A B}=-\sigma_{B A}=\sigma$. Thus, Eq. 2 can be rewritten as follows (Eq. 3):

$E_{R}=\sigma\left(T_{1}-T_{2}\right)$ 
From Eq. 3 it is possible to obtain one of the temperatures, for example, $T_{1}$, if the other (reference) temperature (in this case $T_{2}$ ) is known. Thus, Eq. 3 can be written for $T_{1}$ as follows (Eq. 4):

$\mathrm{T}_{1}=\mathrm{T}_{2}+\frac{\mathrm{E}_{\mathrm{R}}}{\sigma} ;$ if $\sigma \neq 0$

The value of $E_{R}$ is obtained through a previous calibration of the system, in which each voltage value has a corresponding temperature. The calibration methods are also based on Eq. 3 and the aim is to correlate each temperature with a voltage value. The resulting graph obtained through this procedure is commonly called "the thermocouple calibration curve."

The same analysis previously described for a basic thermocouple circuit can be adopted for the workpiece-tool thermocouple method, as performed by Kaminise et al. [17] aiming to study the influence of the toolholder material on the tool-chip interface temperature in turning. The method developed by Kaminise and colleagues [17] to obtain the tool-chip interface temperature will be described in detail below, since it was the technique used in this investigation.

A schematic representation of a thermoelectric circuit in a tool-workpiece thermocouple system is shown in Fig. 4.

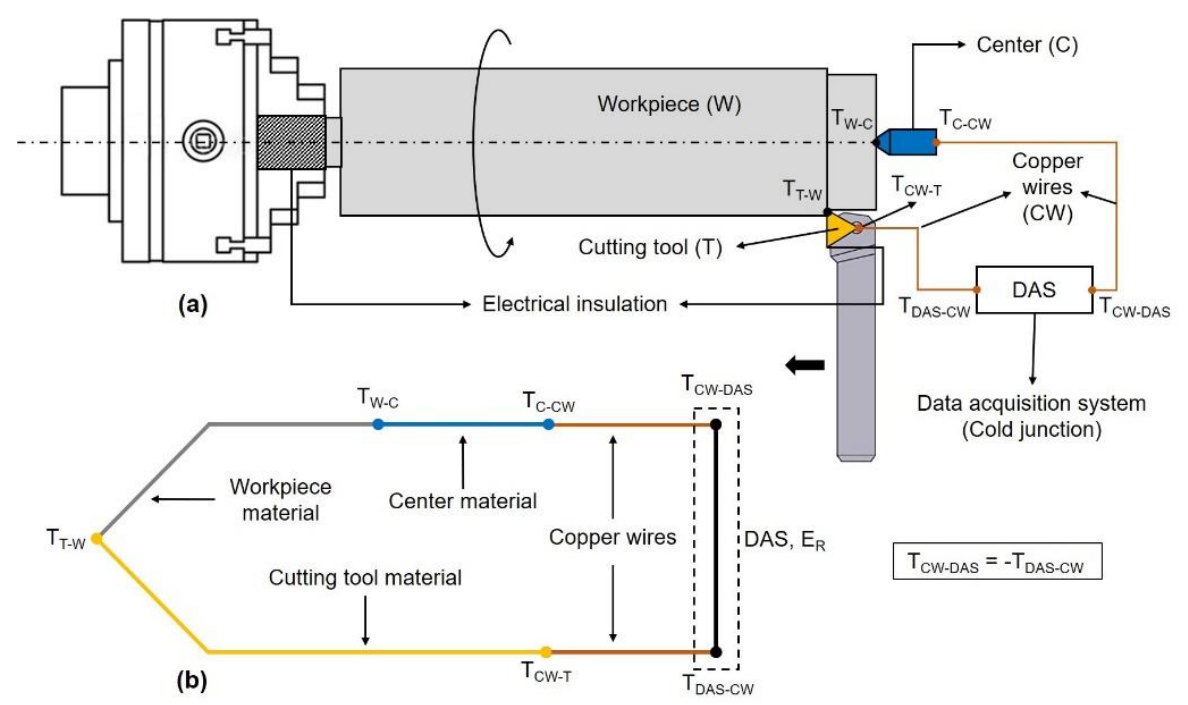

Figure 4. (a) Schematic representation of a thermoelectric circuit in a tool-workpiece thermocouple system and (b) circuit simplification showing its elements and thermojunctions.

It can be noted that, besides the tool-workpiece contact, the circuit is composed of different materials connected by secondary junctions. On analyzing the voltage produced by each thermojunction in Fig. 4(b), it is possible to obtain the resulting electromotive force, $E_{R}$, as previously described:

$\mathrm{E}_{\mathrm{R}}=\mathrm{E}_{\mathrm{T}-\mathrm{W}}\left(\mathrm{T}_{\mathrm{T}-\mathrm{W}}\right)+\mathrm{E}_{\mathrm{W}-\mathrm{C}}\left(\mathrm{T}_{\mathrm{W}-\mathrm{C}}\right)+\mathrm{E}_{\mathrm{C}-\mathrm{CW}}\left(\mathrm{T}_{\mathrm{C}-\mathrm{CW}}\right)+\mathrm{E}_{\mathrm{CW}-\mathrm{DAS}}\left(\mathrm{T}_{\mathrm{CW}-\mathrm{DAS}}\right)+\mathrm{E}_{\mathrm{DAS}-\mathrm{CW}}\left(\mathrm{T}_{\mathrm{DAS}-\mathrm{CW}}\right)+\ldots$ ... $+\mathrm{E}_{\mathrm{CW}-\mathrm{T}}\left(\mathrm{T}_{\mathrm{CW}-\mathrm{T}}\right)$

As $E_{C W-D A S}=-E_{D A S-C W}$ Eq. 5 is reduced to Eq. 6: 
The factors in Eq. 6 represent the voltages produced by each thermojunction. Each factor is dependent on the corresponding temperature and the resulting voltage varies according to the voltage produced at each thermojunction [21]. Thus, when determining the temperature at $\mathrm{T}_{\mathrm{T}-\mathrm{W}}$, it is important to consider the influence of the secondary thermojunctions on the $E_{R}$ value. Kaminise et al. [17] proposed an alternative to offset the voltages produced at the secondary thermojunctions. They added a couple of new elements to the circuit composed of workpiece and lathe center materials, as shown in Fig. 5.

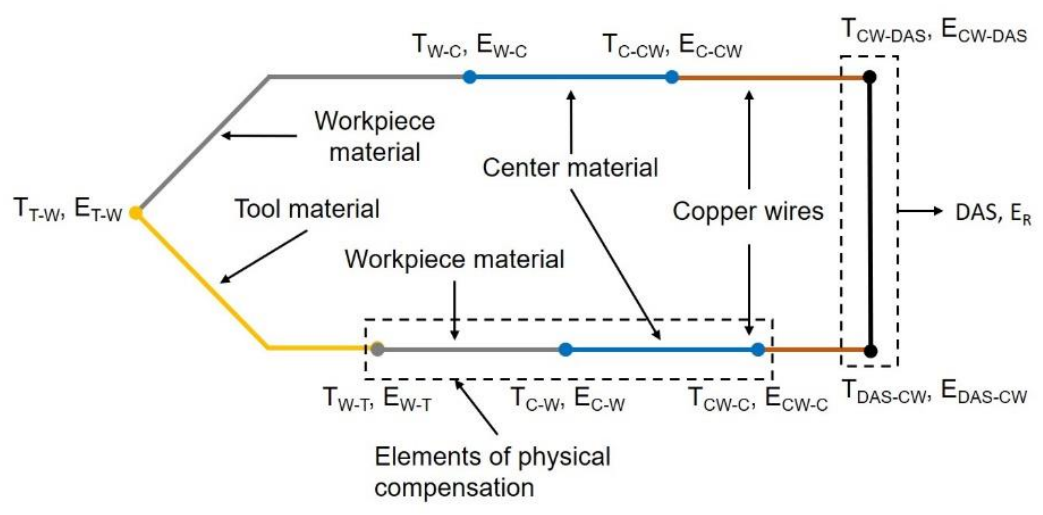

Figure 5. Tool-workpiece thermoelectric circuit with physical compensation [17].

On applying the Kirchhoff law to the circuit of Fig. 5, Eq. 7 is obtained:

$\mathrm{E}_{\mathrm{R}}=\mathrm{E}_{\mathrm{T}-\mathrm{W}}+\mathrm{E}_{\mathrm{W}-\mathrm{C}}+\mathrm{E}_{\mathrm{C}-\mathrm{CW}}+\mathrm{E}_{\mathrm{CW}-\mathrm{DAS}}+\mathrm{E}_{\mathrm{DAS}-\mathrm{CW}}+\mathrm{E}_{\mathrm{CW}-\mathrm{C}}+\mathrm{E}_{\mathrm{C}-\mathrm{W}}+\mathrm{E}_{\mathrm{W}-\mathrm{T}}$

Considering that the temperatures of the furthermost junctions ( $T_{W-C}, T_{C-C W}, T_{C W-D A S}, T_{D A S-C W}, T_{C W}$ $c$ and $T_{C-w}$ ) do not vary over time, and that they are at the same temperature (e.g., at room temperature), i.e., $\mathrm{T}_{\mathrm{W}-\mathrm{C}}=\mathrm{T}_{\mathrm{C}-\mathrm{CW}}=\mathrm{T}_{\mathrm{CW}-\mathrm{DAS}}=\mathrm{T}_{\mathrm{DAS}-\mathrm{CW}}=\mathrm{T}_{\mathrm{CW}-\mathrm{C}}=\mathrm{T}_{\mathrm{C}-\mathrm{W}}=$ constant, then $\mathrm{E}_{\mathrm{W}-\mathrm{C}}=\mathrm{E}_{\mathrm{C}-\mathrm{CW}}=\mathrm{E}_{\mathrm{CW}}$ $D A S=E_{D A S-C W}=E_{C W-C}=E_{C-W} . A_{s} E_{W-C}=-E_{C-W}, E_{C W-D A S}=-E_{D A S-C W}$ and $E_{C W-C}=-E_{C-C W}, E_{q} .7$ is reduced, as shown in Eq. 8.

$E_{R}=E_{T-W}\left(T_{T-W}\right)+E_{W-T}\left(T_{W-T}\right)$

Since the junctions T-W and W-T are composed of the same materials, their Seebeck coefficients have the same value $(\sigma)$. Thus, Eq. 8 can be rewritten for the temperature at the tool-chip interface $\mathrm{T}_{\text {int }}=\mathrm{T}_{\mathrm{T}-\mathrm{W}}$, as in Eq. 9.

$\mathrm{T}_{\text {int }}=\mathrm{T}_{\mathrm{W}-\mathrm{T}}+\frac{\mathrm{E}_{\mathrm{R}}}{\sigma}$ 
The tool-chip interface temperature, $\mathrm{T}_{\text {int }}$, can therefore be obtained by means of the resultant voltage, $E_{R}$, the temperature at the cutting tool-compensation element junction, $T_{W-T}$ and the Seebeck constant, $\sigma$.

It is important to mention that $\mathrm{T}_{\mathrm{W}-\mathrm{T}}$ can vary during the cutting process, mainly in the case of inserts, in which the junction W-T is close to the cutting zone. Thus, not only in the calibration step but also in the cutting step, it is necessary to monitor and register this temperature in order to include it to calculate $\mathrm{T}_{\text {int }}$.

The next section describes the materials used in this investigation and the procedures applied to obtain the tool-chip interface temperatures when turning quenched and tempered AISI D6 steel under dry and $\mathrm{LN}_{2}$ conditions.

\section{MATERIALS AND METHODS}

The flow diagram shown in Fig. 6 summarizes the activities performed in this investigation, which will be described in greater detail below, together with the materials and equipment used.

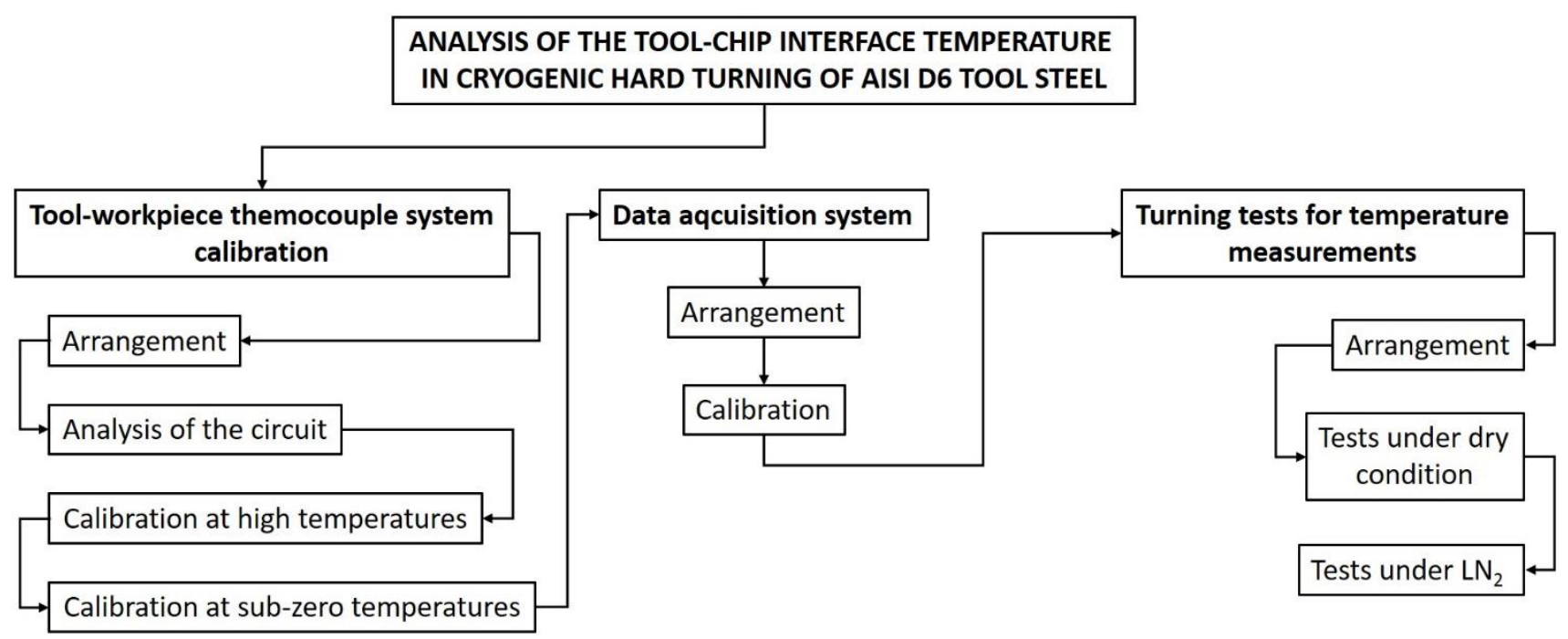

Figure 6. Summary of the activities performed in this investigation.

\subsection{Tool-workpiece thermocouple system calibration}

\subsubsection{Arrangement}

The arrangement to calibrate the tool-workpiece thermocouple system was set up on the same conventional lathe (Romi II-520) used for the turning tests. The method developed by Kaminise at al. [17] and mentioned in the introduction section was reproduced and used in this investigation.

Figures $7 \mathrm{a}$ and $7 \mathrm{~b}$ show the main components of the arrangement for calibration at high temperatures. The same configuration was used to calibrate the system at sub-zero temperatures, but the torch was replaced with a copper delivery nozzle. It should be noted that Fig. 7a represents a top view of the system, but with the modifier live center turned $90^{\circ}$ counterclockwise to better show the internal parts. 


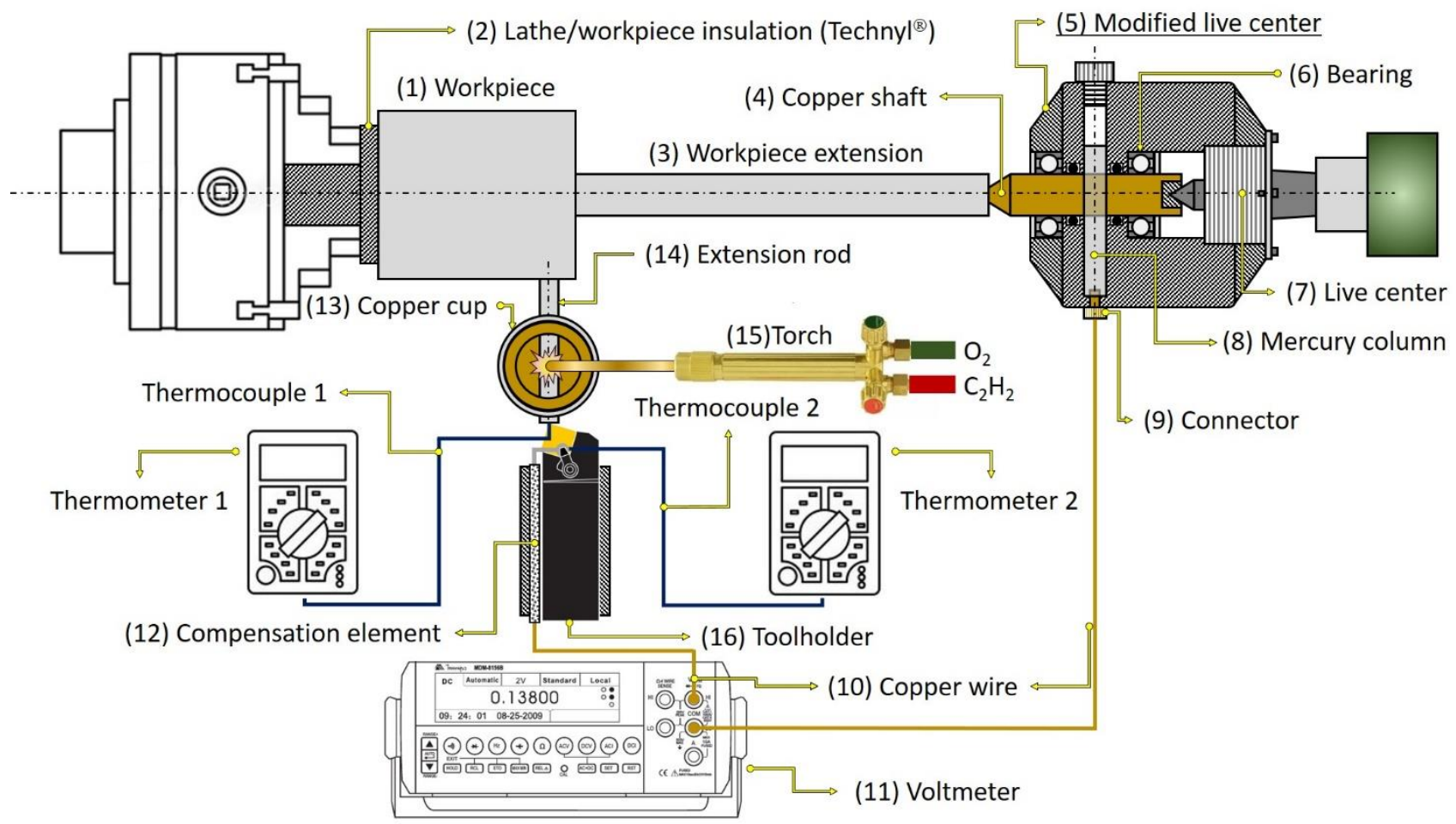

(a)

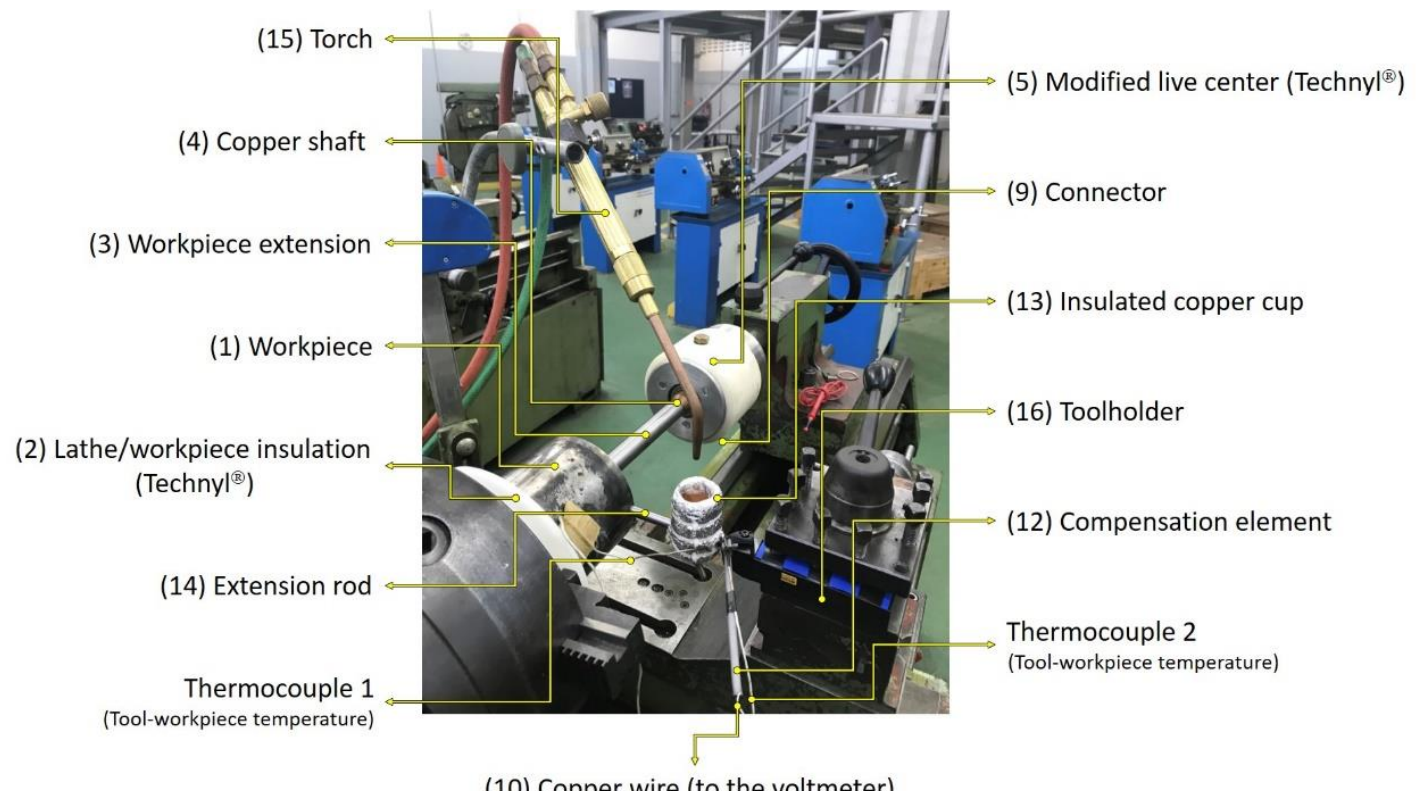

(10) Copper wire (to the voltmeter)

(b)

Figure 7. (a) Arrangement of equipment used to calibrate the tool-workpiece thermocouple system and (b) Experimental set up.

The workpiece consisted of a quenched and tempered AISI D6 tool steel ( $57 \mathrm{HRC}$ ) cylindrical bar with a diameter of $109.8 \mathrm{~mm}$ and length of $133 \mathrm{~mm}$ (1). To prevent a temperature variation at the 
contact between the workpiece and the rotating cooper shaft (4) during the calibration and turning tests, these parts were kept at a distant from each other by means of a workpiece extension ( $\varnothing 25$ $\mathrm{mm} \times 200 \mathrm{~mm}$ ) (3), which was welded to the workpiece. For the calibration procedure, an extension $\operatorname{rod}(\varnothing 10 \mathrm{~mm} \times 95 \mathrm{~mm}$ ) (14) of the same workpiece material was also fixed to the workpiece in order to accelerate the temperature change. A copper cup (13) insulated with glass wool was attached to the extension rod with the purpose of concentrating the heat supplied by the torch, or the mist of liquid nitrogen in the case of sub-zero calibration. A full form PCBN insert SNGN 120412S02520M 7925 manufactured by Sandvik Coromant was used as the cutting tool. Table 1 gives the dimensions, and it can be observed that the insert has a chamfered edge of $0.25 \mathrm{~mm} \times 20^{\circ}$. This information will be particularly important in the turning tests because the chip formation occurs on the chamfer, where the resultant side rake angle is extremely negative $\left(-26^{\circ}\right)$. The insert was clamped on a toolholder code DSBR 2525M 12, providing the insert-toolholder geometry shown in the second part of Table 1.

Table 1. Geometric features of the insert and toolholder.

\begin{tabular}{|c|c|c|c|c|c|c|}
\hline \multicolumn{7}{|c|}{ Insert dimensions } \\
\hline $\begin{array}{l}\text { Chamfer } \\
\text { angle }\left(^{\circ}\right)\end{array}$ & $\begin{array}{l}\text { Chamfer } \\
\text { length } \\
(\mathrm{mm})\end{array}$ & $\begin{array}{l}\text { Inscribed circle } \\
\text { diameter } \\
(\mathrm{mm})\end{array}$ & $\begin{array}{l}\text { Corner radius } \\
(\mathrm{mm})\end{array}$ & $\begin{array}{l}\text { Cutting edge effective } \\
\text { length }(\mathrm{mm})\end{array}$ & $\begin{array}{l}\text { Insert thickness } \\
(\mathrm{mm})\end{array}$ & \\
\hline 20 & 0.25 & 12.7 & 1.191 & 11.5 & 4.763 & \\
\hline \multicolumn{7}{|c|}{ Insert-toolholder geometry } \\
\hline $\begin{array}{l}\text { Approach } \\
\text { angle, } \\
\kappa_{r}\end{array}$ & $\begin{array}{l}\text { Nose } \\
\text { angle, } \\
\varepsilon r\end{array}$ & $\begin{array}{l}\text { Side cutting } \\
\text { edge angle, } \\
\kappa_{r}^{\prime}\end{array}$ & $\begin{array}{l}\text { Main clearance } \\
\text { angle, } \\
\alpha_{0}\end{array}$ & $\begin{array}{l}\text { Wedge angle, } \\
\beta_{0}\end{array}$ & $\begin{array}{l}\text { Side rake angle, } \\
\gamma_{0}\end{array}$ & $\begin{array}{l}\text { Back } \\
\text { rake } \\
\text { angle, } \\
\lambda_{s}\end{array}$ \\
\hline $15^{\circ}$ & $90^{\circ}$ & $15^{\circ}$ & $6^{\circ}$ & $90^{\circ}$ & $-6^{\circ}$ & $-6^{\circ}$ \\
\hline
\end{tabular}

It can also be observed in Fig. 7 that a compensation element (12) is used to close the electrical circuit between the insert and the copper wire (10), which is connected to the voltmeter (11). The voltmeter measures the resultant electromotive force in the circuit. The compensation element was made of a thermoplastic tube filled with compacted chips of the workpiece material. The end, close to the insert, is composed of a small piece also made of the workpiece material and attached to the insert by means of the toolholder clamp, together with the end of thermocouple 2 (K-type), which measures the temperature variation at this point during the calibration. Thermocouple 1 (K-type) measures the temperature variation at the contact point between the insert and the extension rod (14). In order to ensure the closing of the circuit, even though the workpiece is rotating, a modified live center was used (5). In this device there is a copper shaft (4) supported by two ball bearings (6). This shaft is in contact with the workpiece extension and rotates with it when the lathe is turned on, in the case of turning tests. The copper shaft then passes through a column of liquid mercury (8) that is also in contact with a copper connector (9) at the bottom of the modified live center, to which a copper wire (10) is connected, which passes to the second connection of the voltmeter, closing the electrical circuit of the system. It is important to highlight that all of these elements are isolated from the lathe using components manufactured of Technyl ${ }^{\circledR}$ (but another type of insulator could be used). 


\subsubsection{Analysis of the circuit}

Figure 8 shows a representative electrical circuit for the tool-workpiece thermocouple system used in this investigation.

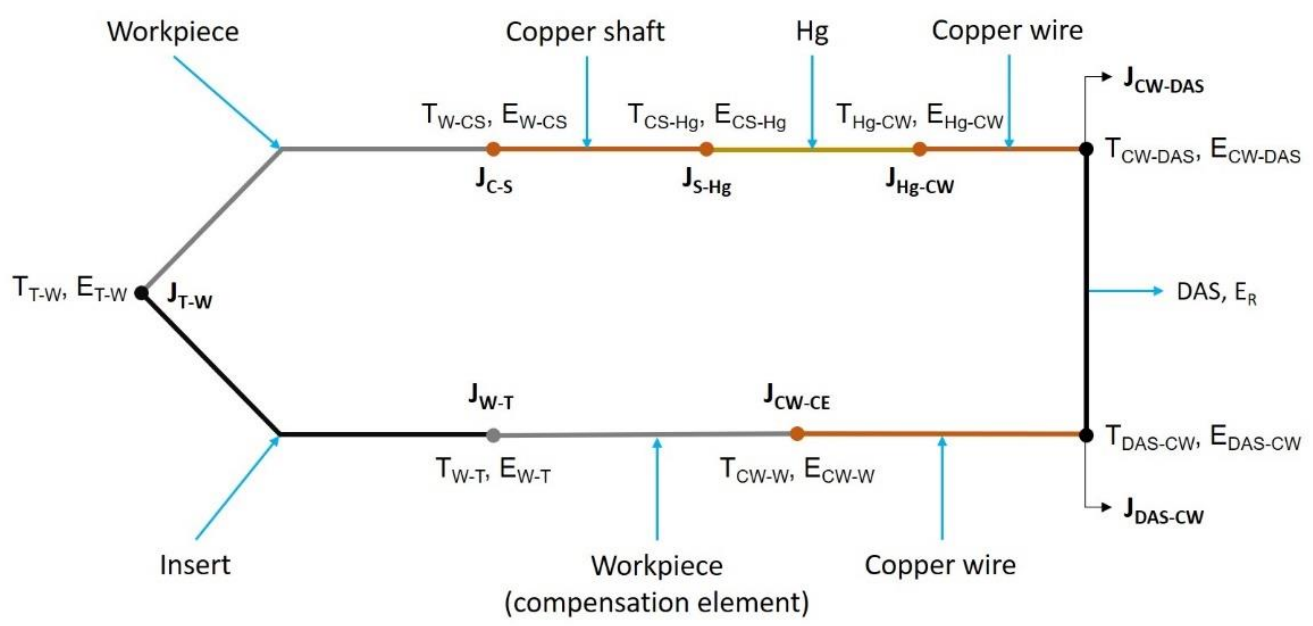

Figure 8. Electrical circuit for the tool-workpiece thermocouple system.

The circuit is basically composed of four different materials with eight thermoelectric junctions (e.g., $\mathbf{J}_{W-\mathrm{T}}$ in Fig. 8). Considering each junction as a source of FEM and using the Kirchhoff law, gives Eq. 10.

$$
\begin{aligned}
& \mathrm{E}_{\mathrm{R}}=\mathrm{E}_{\mathrm{T}-\mathrm{W}}\left(\mathrm{T}_{\mathrm{T}-\mathrm{W}}\right)+\mathrm{E}_{\mathrm{W}-\mathrm{CS}}\left(\mathrm{T}_{\mathrm{W}-\mathrm{CS}}\right)+\mathrm{E}_{\mathrm{CS}-\mathrm{Hg}}\left(\mathrm{T}_{\mathrm{CS}-\mathrm{Hg}}\right)+\mathrm{E}_{\mathrm{Hg}-\mathrm{CW}}\left(\mathrm{T}_{\mathrm{Hg}-\mathrm{CW}}\right)+\mathrm{E}_{\mathrm{CW}-\mathrm{DAS}}\left(\mathrm{T}_{\mathrm{CW}-\mathrm{DAS}}\right)+\cdots \\
& \cdots+\mathrm{E}_{\mathrm{DAS}-\mathrm{CW}}\left(\mathrm{T}_{\mathrm{DAS}-\mathrm{CW}}\right)+\mathrm{E}_{\mathrm{CW}-\mathrm{W}}\left(\mathrm{T}_{\mathrm{CW}-\mathrm{W}}\right)+\mathrm{E}_{\mathrm{W}-\mathrm{T}}\left(\mathrm{T}_{\mathrm{W}-\mathrm{T}}\right)
\end{aligned}
$$

In this investigation, it was assumed that $T_{W-C S}=T_{C S-H g}=T_{H g-C W}=T_{C W-D A S}=T_{D A S-C W}=T_{C W-W}=T_{\text {room }}$ $=$ cte.

From the principle that an inversion in the order of the elements that compose the circuit means a change in polarity of the FEM generated, e.g., $E_{C W-D A S}=-E_{D A S-C W}$, and because the copper shaft and the copper wire are of the same material and the compensation element is comprised of the same material as the workpiece, Eq. 10 can be rewritten as follows (Eq. 11 and 12):

$$
\mathrm{E}_{\mathrm{R}}=\mathrm{E}_{\mathrm{T}-\mathrm{W}}\left(\mathrm{T}_{\mathrm{T}-\mathrm{W}}\right)+\mathrm{E}_{\mathrm{W}-\mathrm{CS}}+\mathrm{E}_{\mathrm{CS}-\mathrm{Hg}}-\mathrm{E}_{\mathrm{CS}-\mathrm{Hg}}+\mathrm{E}_{\mathrm{CW}-\mathrm{DAS}}-\mathrm{E}_{\mathrm{CW}-\mathrm{DAS}}-\mathrm{E}_{\mathrm{W}-\mathrm{CS}}+\mathrm{E}_{\mathrm{W}-\mathrm{T}}\left(\mathrm{T}_{\mathrm{W}-\mathrm{T}}\right)
$$

or

$E_{R}=E_{T-W}\left(T_{T-W}\right)+E_{W-T}\left(T_{W-T}\right)$

As described in the introduction section, Eq. 12 can be rewritten as follows (Eq. 13):

$$
E_{R}=\sigma_{T-W} \cdot T_{T-W}+\sigma_{W-T} \cdot T_{W-T}
$$

where $\sigma_{T-W}$ and $\sigma_{W-T}$ are the Seebeck coefficients for the joints $\mathrm{J}_{T-W}$ and $\mathrm{J}_{\mathrm{W}-\mathrm{T}}$, respectively, which have the same value but opposite signs, i.e., $\sigma_{T-W}=-\sigma_{W-T}$. Thus, Eq. 13 becomes Eq. 14: 
$E_{R}=\sigma_{T-W} \cdot T_{T-W}-\sigma_{T-W} \cdot T_{W-T}$

Finally, for $\sigma_{T}-\mathrm{w}=\mathrm{K}$, where "K" is the Seebeck coefficient for the tool-workpiece thermocouple, Eq. 14 can be rearranged for the tool-chip interface temperature as follows (Eq. 15 and 16):

$T_{T-W}=T_{W-T}+\frac{E_{R}}{K}$

or

$K=\frac{E_{R}}{T_{T-W}-T_{W-T}}$

Thus, during the calibration process it is necessary to monitor the temperatures at junctions $\left(\mathrm{J}_{\mathrm{T}-\mathrm{W}}\right.$ and $\left.J_{W-T}\right)$ and $E_{R}$ at the same time, in order to obtain the value of $K$, which represents the slope of the straight line $E_{R} \times\left(T_{T-W}-T_{W-T}\right)$, in the case of linear behavior.

\subsubsection{Calibration at high temperatures}

To calibrate the tool-workpiece thermocouple system at high temperatures, the tool-workpiece junction was heated using an oxyacetylene torch, as shown in Figure 9. It should be noted that the flame is directed to the extension rod, which is partially inside the copper cup. Thus, the temperature at the tool-workpiece junction is increased (by conduction).

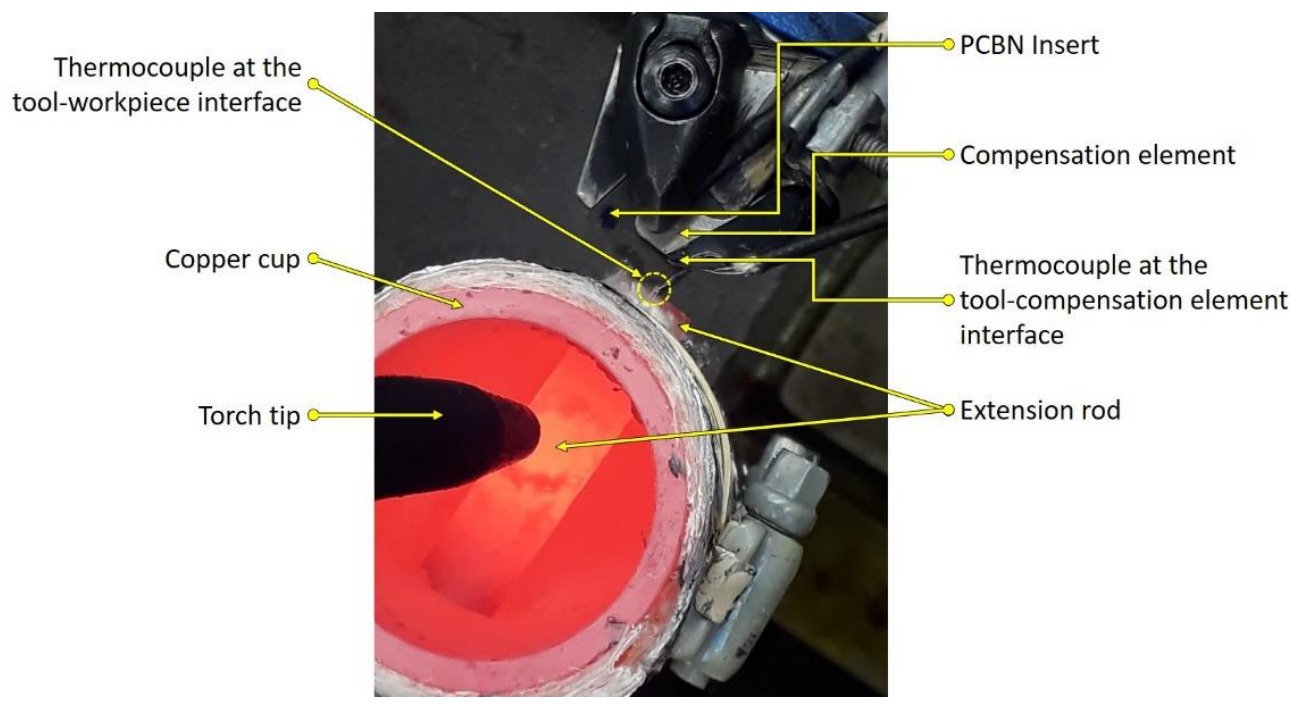

Figure 9. Details of the process of calibration at high temperatures.

The temperatures $\mathrm{T}_{T-\mathrm{W}}$ and $\mathrm{T}_{\mathrm{W}-\mathrm{T}}$ were monitored using digital multimeters (Minipa ET-1400). The voltages generated by the tool-workpiece thermocouple circuit were measured with an Agilent 34405A multimeter. The data were registered by means of photos taken of the displays of these devices at a frequency of around 1 photo per second. 


\subsubsection{Calibration at sub-zero temperatures}

Although the tool-chip interface temperatures during machining will not assume sub-zero values, calibration was performed under this condition in order to check the correspondence between the experimental points obtained at low temperatures and those obtained at high temperatures, thereby improving the correlation index of the fitted curve. Thus, the calibration at sub-zero temperatures was performed using $\mathrm{LN}_{2}$ as the cooling fluid to refrigerate the extension rod and the tool-workpiece thermocouple, using a system developed by Leadebal et al. [10] and Fernandes et al. [22]. Figure 10 shows how liquid nitrogen was applied, as a mist at $1.8 \mathrm{bar}, 38 \mathrm{~L} / \mathrm{h}$ and $-196{ }^{\circ} \mathrm{C}$, to calibrate the system.

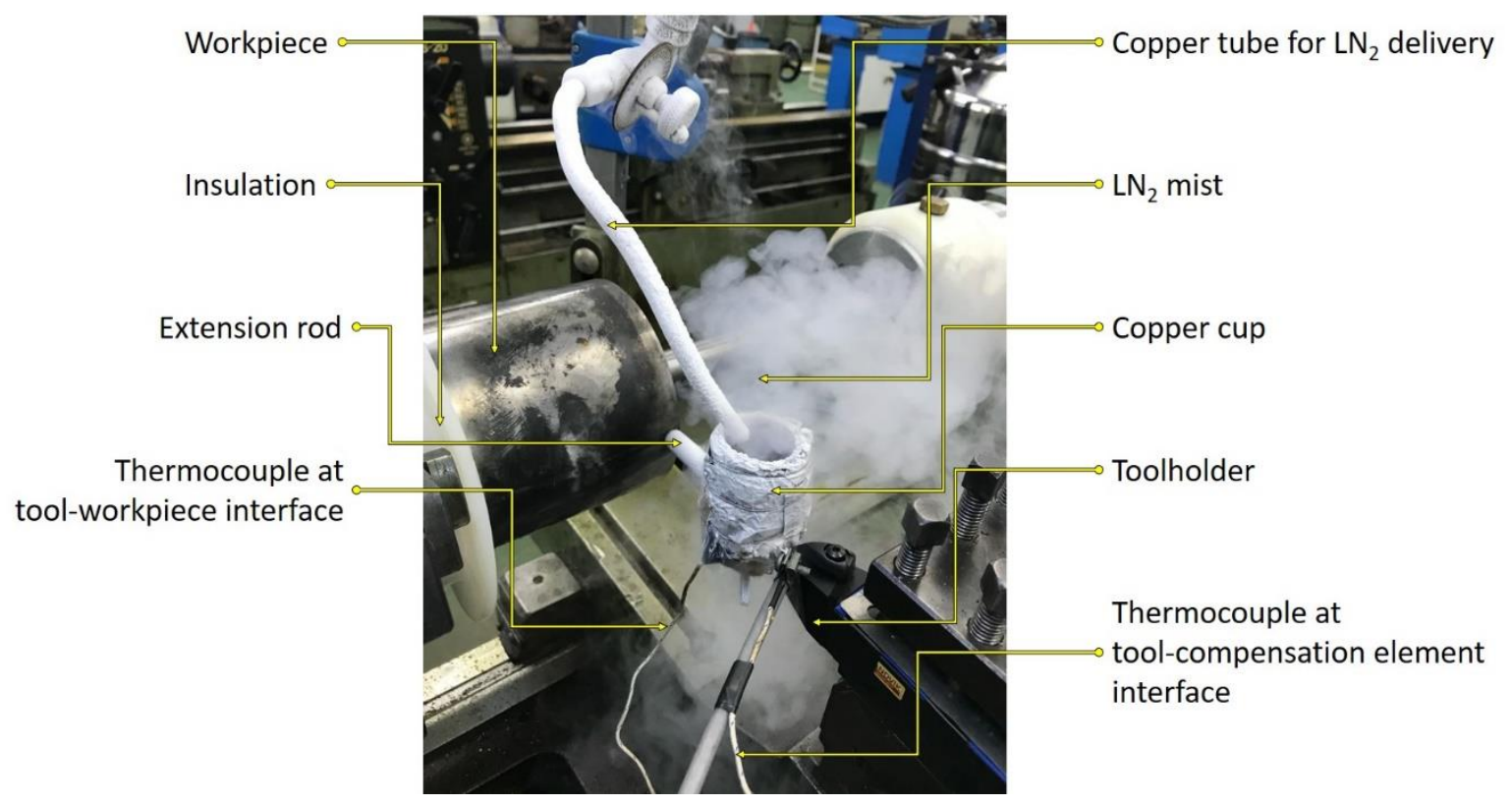

Figure 10. Details of the calibration process at sub-zero temperatures.

Since the temperatures reach sub-zero values in this step, the instrument used to measure them was a thermometer Agilent 34970A, which is able to measure cryogenic temperatures with a resolution of $0.1^{\circ} \mathrm{C}$. The multimeter used to measure the resultant voltage was the same as that used for high temperature calibration (Agilent 34405A). The values were recorded using the same procedure applied in the case of high temperature calibration.

After these two procedures, the two calibration curves $\left(T_{T-W}-T_{W-T}\right) \times E_{R}$ were plotted on a single chart, which was used to obtain the calibration curve for the two-workpiece thermocouple system and then to obtain the chip-tool interface temperature.

\subsection{Data acquisition system}

The data acquisition system used for the calibration and to measure the tool-chip interface temperature was developed and constructed based on the Arduino Uno platform, with low-cost and open-source software and hardware. In order to monitor visually the temperatures in real time, the 
platform was integrated with Excel ${ }^{\circledR}$ by means of the app PLX-DAQ. Thus, the system was able to capture the analog signals generated by the tool-workpiece thermocouple system, promote a static gain, digitalize the signals for processing by the ATmega328 P microcontroller present in the Arduino board and display the results in Excel ${ }^{\circledR}$. Further details on the data acquisition system and its calibration are given below.

\subsubsection{Arrangement}

To assemble the data acquisition system the following equipment was used:

- An Arduino UNO R3 board equipped with an ATmega328 P microcontroller to receive and process the analog signals from the thermocouples.

- An Avia Semiconductors HX711 module amplifier and A/D converter to amplify the analog signals coming from the thermocouples.

- A Maxim Integrated MAX31855 module to amplify and digitalize the analog signal coming from the K-type thermocouple welded on the compensation element.

- Arduino IDE 1.8.8 app to edit the codes for data acquisition.

- The Parallax Inc PLX-DAQ software program to integrate the Arduino platform and the Excel $^{\circledR}$ app.

Figures $11 \mathrm{a}$ and $11 \mathrm{~b}$ show the circuit arrangement and the physical circuit, respectively.

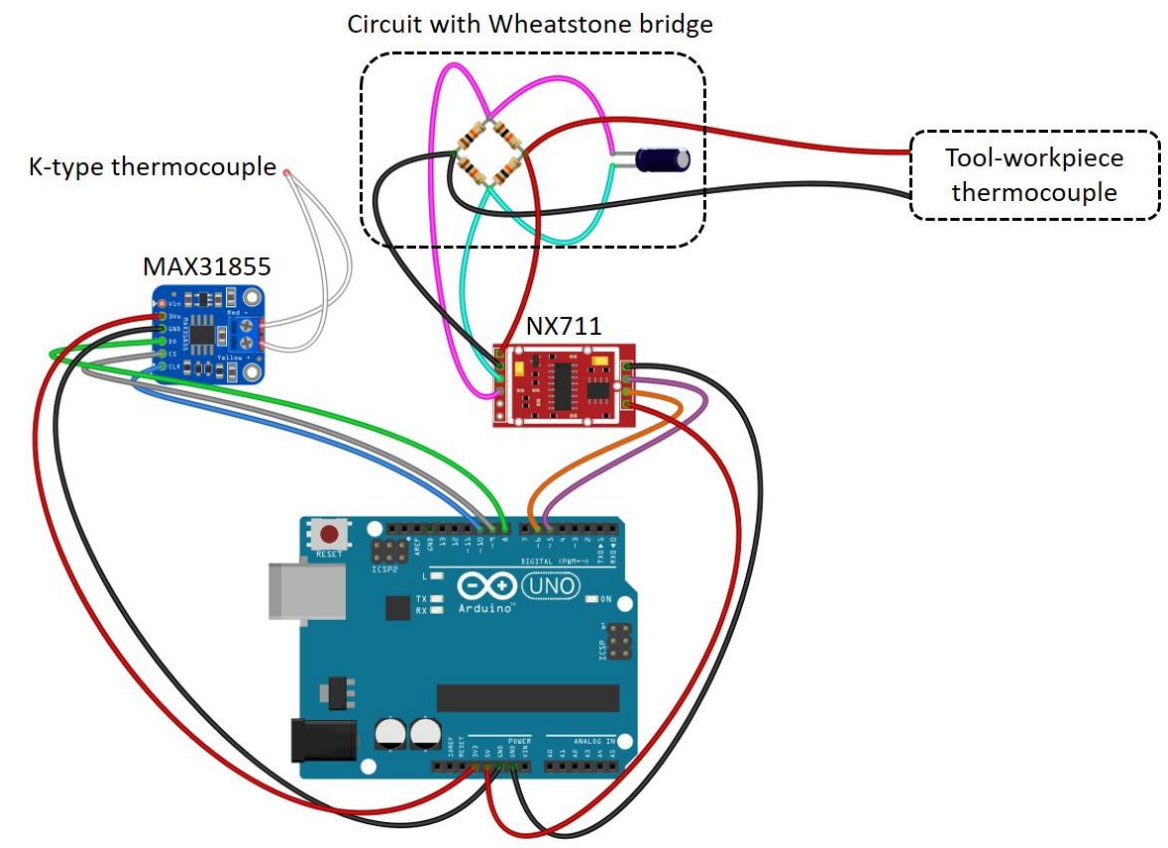

(a) 


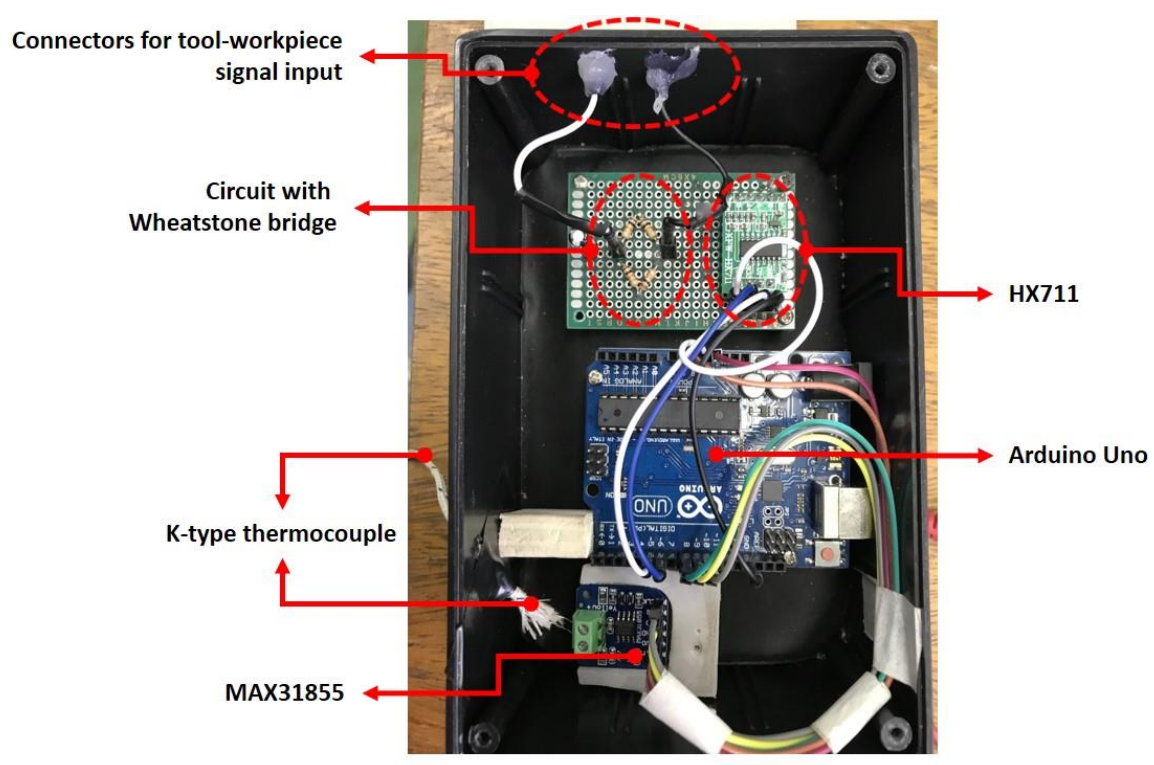

(b)

Figure 11. Data acquisition circuit: (a) connection diagram and (b) physical circuit.

\subsubsection{Calibration}

The temperature at the tool-chip interface is dependent on both the voltage $\left(E_{R}\right)$ generated in the tool-workpiece thermocouple system and the temperature measured by the K-type thermocouple at the compensation element. Since it was designed for K-type thermocouples, the integrated circuit MAX31855 was previously calibrated to provide temperature values according to the input voltage signals. In contrast, the integrated circuit HX711 is more appropriate for load cell applications, i.e., for mass/weight measurements. However, in this investigation, it amplified the voltage signal coming from the tool-workpiece thermocouple system and delivered it to the Arduino Uno board. The resulting voltage $\left(E_{R}\right)$ is applied in the calibration equation together with the temperature measured by the thermocouple placed at the end of the compensation element end, which is in contact with the PCBN insert, providing the tool-chip interface temperature.

In order to minimize the measurement error, the data acquisition system was calibrated. In this procedure, the acquisition module was connected to a laptop (Dell Inspiron 5558) with a $2.2 \mathrm{GHz}$ processor and submitted to different voltages provided by an Agilent E3631A voltage supply. The voltage values supplied were then plotted against the values given by the acquisition system. Thus, it was possible to calculate the error of the acquisition system. The reference voltage ranged from 0 to $16 \mathrm{mV}$ (17 values). To minimize the error, a correction factor present in the HX711 code was modified eight times in order to obtain the lowest value for the error. The correction factor that provided the lowest error was considered for the final tests.

\subsection{Turning tests for temperature measurements}

The setup for temperature measurements was practically the same used to calibrate the system (see Fig. 12) with some mandatory modifications, such as: (i) the extension rod was removed, (ii) the data acquisition system was connected to the experimental setup, (iii) the K-type thermocouple was connected to the data acquisition system, (iv) the toolholder was placed upside down on the lathe turret in order to prevent chip accumulation and avoid an accident (liquid nitrogen directed towards 
the lathe operator). Thus, the $\mathrm{LN}_{2}$ delivery nozzle was placed from top to bottom towards the flank face of the insert, as shown in the detail of Fig. 12.

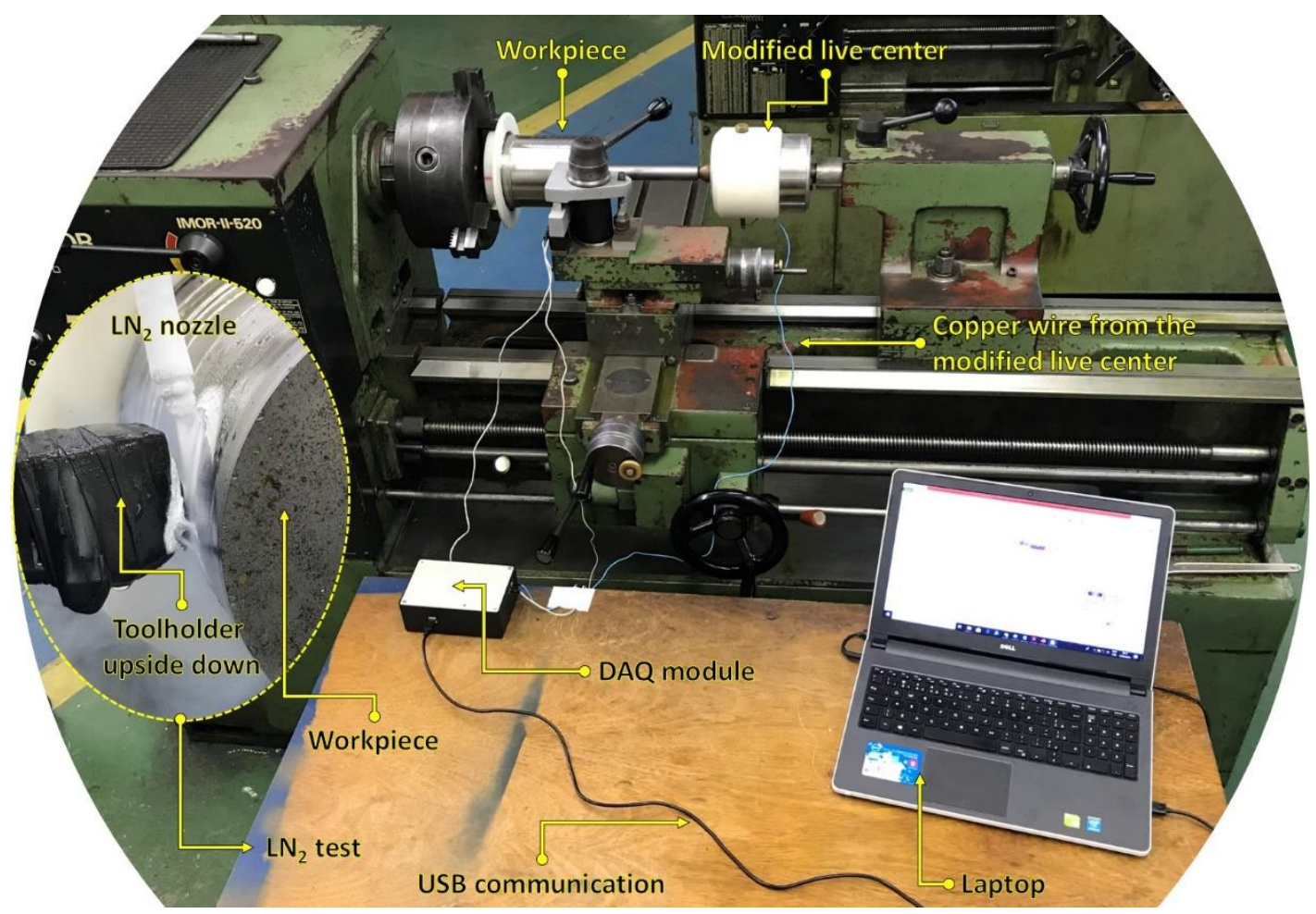

Figure 12. Setup for the tool-chip interface temperature measurement.

The turning trials were carried out with a cylindrical bar of quenched and tempered AISI D6 tool steel with an initial diameter of $109.8 \mathrm{~mm}$ and average hardness of $57 \mathrm{HRC}$. The bar was divided into three sections each of $\sim 24 \mathrm{~mm}$, according to Fig. 13. It can be noted that one of these sections was used for pre-tests in order to verify the behavior of the system when turning and adjusting it, if necessary, before the final tests. The other two sections were used to perform the final tests under dry and $\mathrm{LN}_{2}$ conditions. The sections were separated by circular grooves with $5 \mathrm{~mm}$ of depth, which enabled the depth of cut to be set.

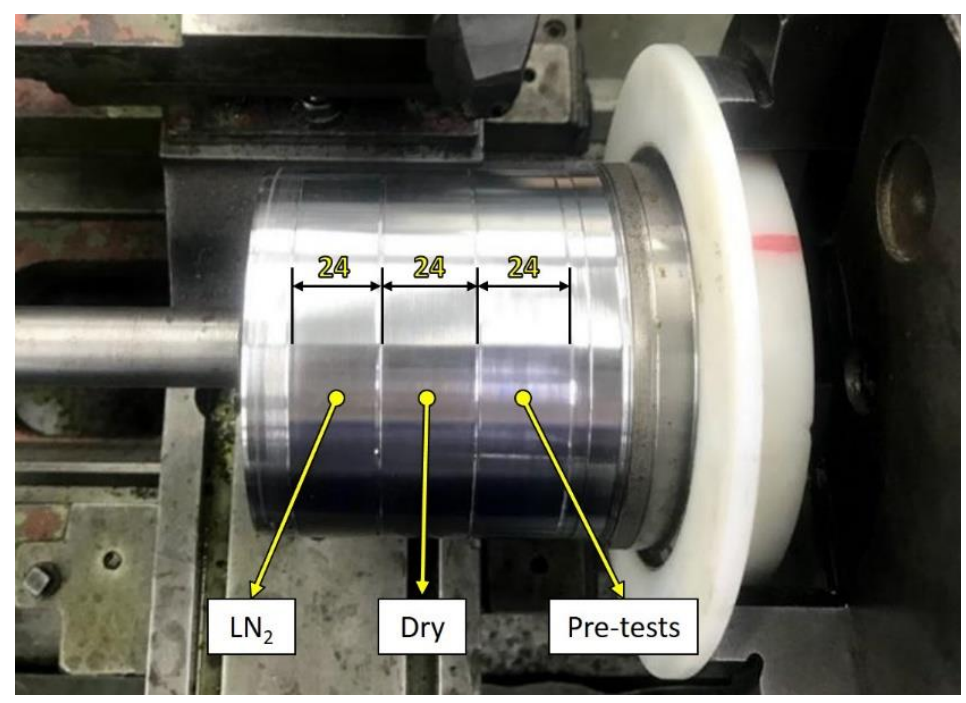

Figure 13. Cylindrical bar used for the turning tests divided into three sections. 
Three tests were performed for each condition ( $\mathrm{LN}_{2}$ and dry) with different cutting speeds while keeping the feed rate $(f=0.1 \mathrm{~mm} / \mathrm{rev})$ and depth of cut $\left(a_{p}=0.1 \mathrm{~mm}\right)$ constant. The same type of PCBN insert used in the calibration tests was applied in the turning tests. Table 2 summarizes the cutting conditions of the tests performed.

Table 2. Turning tests.

\begin{tabular}{|c|c|c|c|}
\hline & Test & $\begin{array}{l}\text { Cutting } \\
\text { strategy }\end{array}$ & $\begin{array}{l}\text { Cutting speed } \\
(\mathrm{m} / \mathrm{min})\end{array}$ \\
\hline \multirow{6}{*}{ 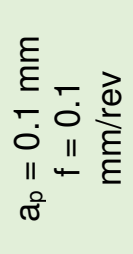 } & 1 & \multirow{3}{*}{ Dry } & 31 \\
\hline & 2 & & 48 \\
\hline & 3 & & 62 \\
\hline & 5 & \multirow{3}{*}{$\mathrm{LN}_{2}$} & 31 \\
\hline & 6 & & 48 \\
\hline & 7 & & 62 \\
\hline
\end{tabular}

It is important to mention that each turning test was performed only once, with a fresh cutting edge for each cutting strategy. Thus, the cutting edge was not replaced when the cutting speed was varied within a cutting strategy. This procedure was adopted because of the difficulties in assembling all the elements of the measuring system (Fig. 14). It can be noted that at one of the ends of the compensation element a curved piece, also made of AISI D6 tool steel, was attached to facilitate its contact with the toolholder clamp. The detail "A" shows the position of the K-type thermocouple tip beneath this curved piece. Fitting these parts together and firmly tightening them was not a simple task. However, considering the machining time for each test and the data acquisition frequency, the number of samples was sufficient to determine the average values for the tool-chip interface temperature and the respective standard deviations.

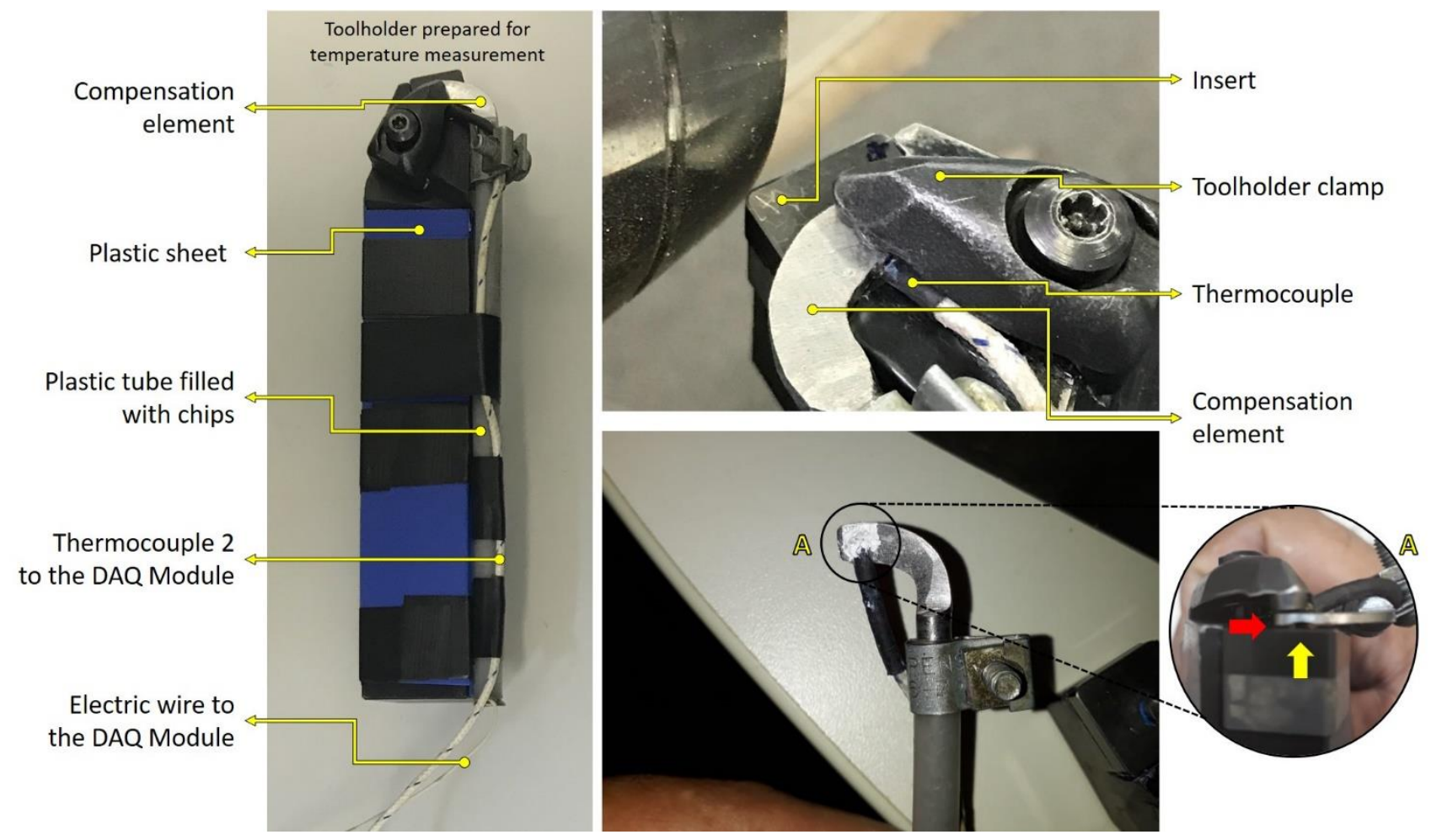

Figure 14. Details of the toolholder with compensation element attached to it. 
Finally, $\mathrm{LN}_{2}$ was delivered on the flank face at a pressure of 1.8 bar and a flow rate of $38 \mathrm{~L} / \mathrm{h}$, using the system described by Leadebal Jr. et al. [9,10].

Section 3 provides the results obtained in this investigation along with a discussion of the main findings.

\section{RESULTS AND DISCUSSION}

Figures 15 and 16 show the values of $T_{1}-T_{2}$ vs voltage for subzero and high temperature calibrations, respectively. $T_{1}$ is the temperature at the extension rod face (see thermocouple 1 in Fig. 8), representing the chip-tool temperature, and $T_{2}$ represents the temperature measured by thermocouple 2 (K-type) at the point of contact between the insert and the compensation element (see Fig. 8).

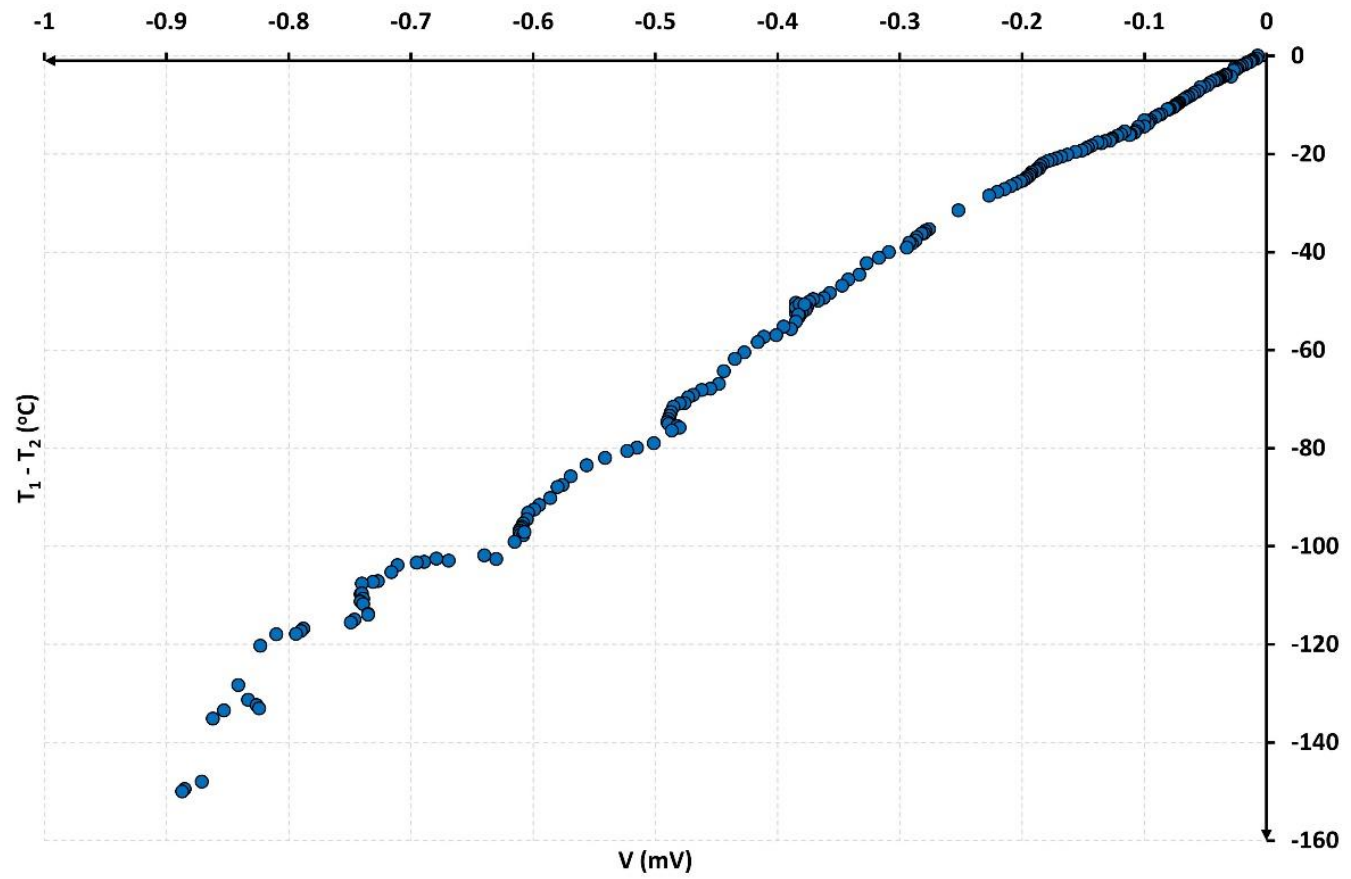

Figure 15. Experimental points for the subzero calibration. 


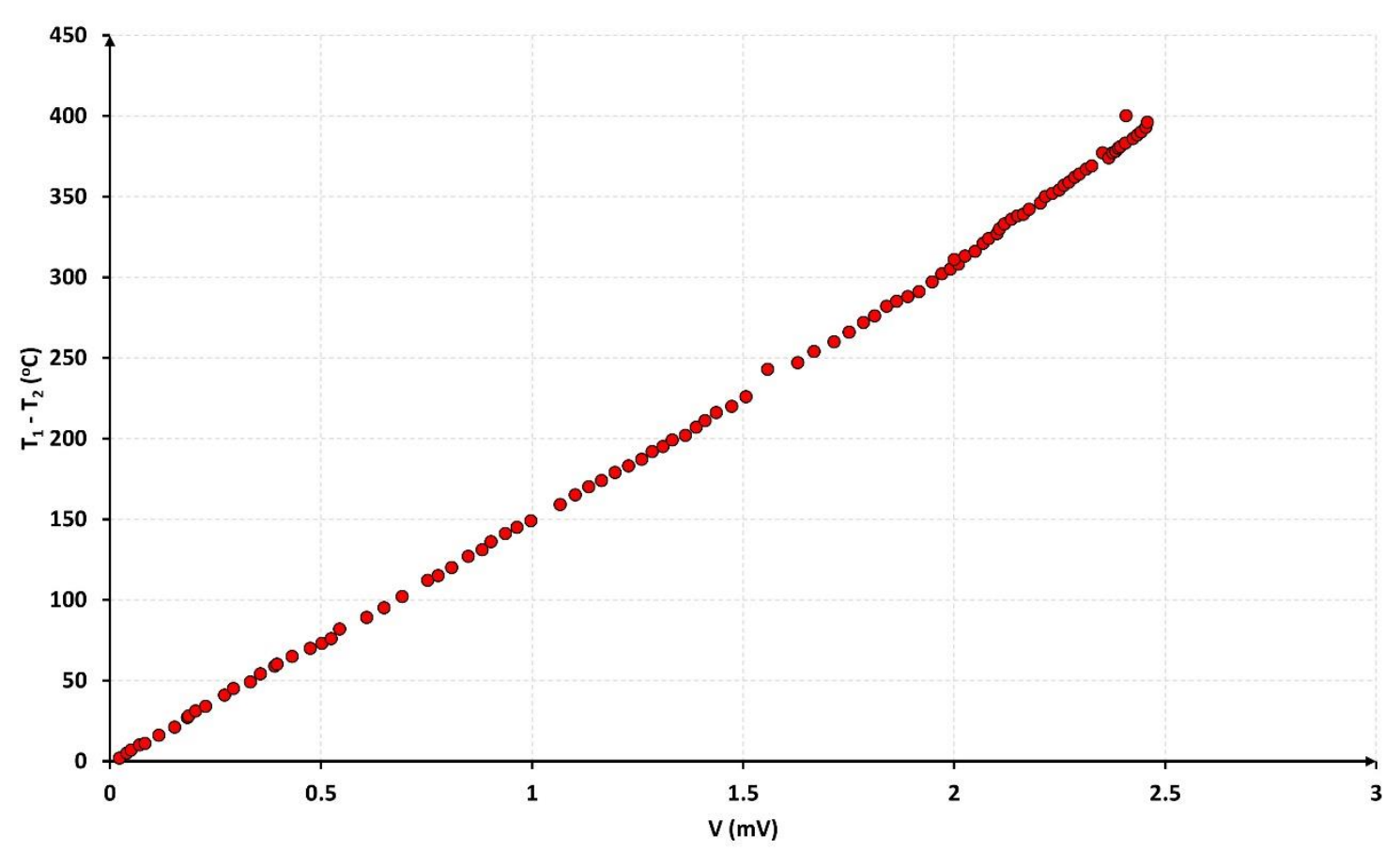

Figure 16. Experimental points for the high temperature calibration.

In order to obtain the calibration curve for the tool-workpiece system, the experimental points for subzero and for high temperature calibrations were combined, giving the chart shown in Fig. 17.

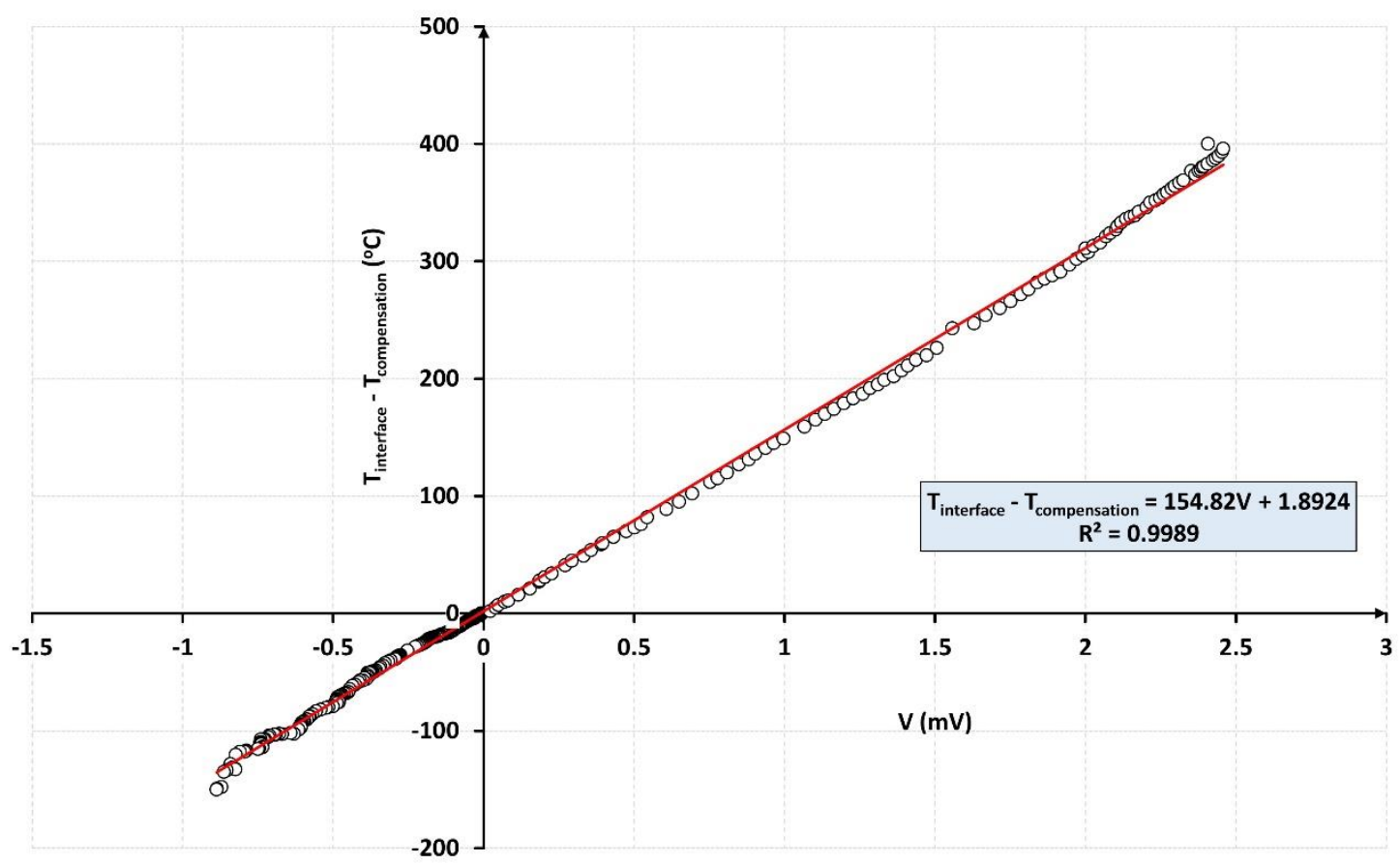

Figure 17. Final calibration curve.

A major issue regarding Fig. 17 is that the maximum temperature that could be reached during the calibration process was around $400{ }^{\circ} \mathrm{C}$, which is relatively low for this investigation, where hardened steel was used as the workpiece. It can be noted that the behavior of the experimental 
points was practically linear up to $\sim 400^{\circ} \mathrm{C}$, which induced us to approximate them to a linear curve, as detailed in the next paragraph. However, previous investigations have shown that the behavior of calibration curves for tool-workpiece thermocouple systems at higher temperatures are not linear, producing a smooth inclination that diminishes their derivative $[17,20]$. Thus, for tool-workpiece thermocouple systems second (or higher)-degree polynomials would provide more representative equations, but these could not be obtained in this study because of the relatively low maximum temperature reached during the calibration. The heat dissipation from the extension rod to the copper cup wall (see Fig. 9) hindered higher temperatures $\left(>400^{\circ} \mathrm{C}\right)$ being reached on the face of the extension rod (in contact with the tool insert nose). Therefore, a linear behavior of the calibration curve was adopted to obtain the tool-chip interface temperatures during the turning tests under dry and $\mathrm{LN}_{2}$ conditions, which may have produced temperatures considered high for the set of cutting parameters used. However, in terms of comparing the two cooling strategies investigated in this study, the system was able to respond satisfactorily.

In Fig. 17, it can also be noted that the experimental points for subzero and high temperatures fit the same linear curve (in red) almost perfectly, and this was used to represent the final calibration curve for the tool-workpiece thermocouple system proposed herein. The calibration equation is also shown on the chart. For $T_{1}-T_{2}=0$, the corresponding voltage is expected to be zero, but the regression curve cuts the ordinate axis at $1.89 \mathrm{mV}$. This minor inconsistency may have occurred due to the dispersion of the experimental data. In order to correct this, the regression curve was shifted to the origin of the coordinate system shown in Fig. 17, maintaining its slope. As a result of this procedure, the final calibration equation used to calculate the tool-chip interface temperature was the following (Eq. 17):

$\mathrm{T}_{\text {interface }}=154.82 \mathrm{~V}-\mathrm{T}_{\text {compensation }}$

Figures 18 to 20 show the evolution of the tool-chip interface temperature over time. On analyzing these charts, the following remarks can be made:

1) A high oscillation in the tool-chip interface temperature occurs with the $\mathrm{LN}_{2}$ strategy.

2) The average tool-chip interface temperature (the steady state considered) increases with the cutting speed for both strategies.

3) It seems that the application of $\mathrm{LN}_{2}$ at the flank face and workpiece contact is able to reduce the tool-chip interface temperature as compared to the dry strategy, although this approach is less effective at higher cutting speeds (48 and $62 \mathrm{~m} / \mathrm{min}$ ). 


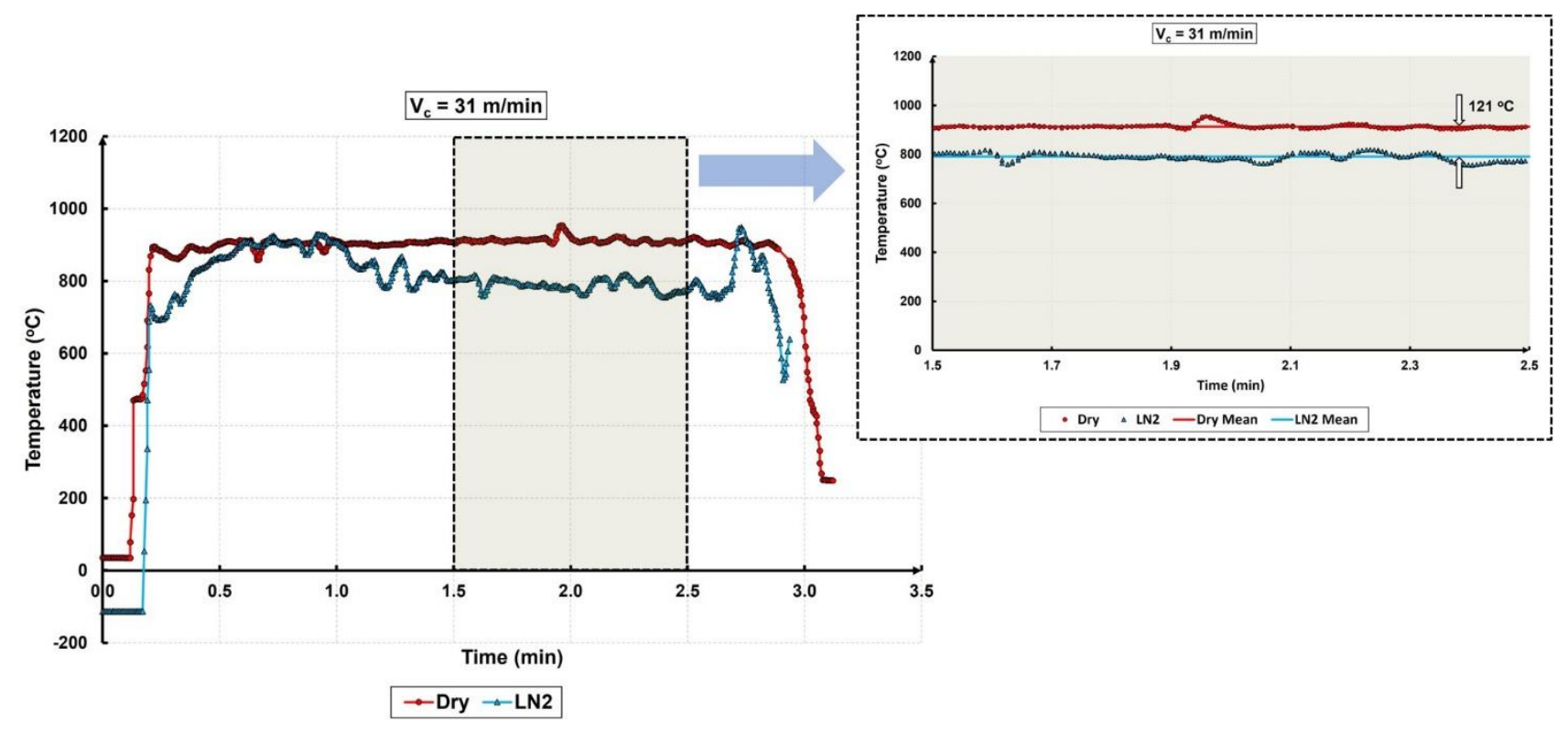

Figure 18. Chip-tool interface temperature vs time for the dry and $L N_{2}$ strategies at $V_{c}=31 \mathrm{~m} / \mathrm{min}$.

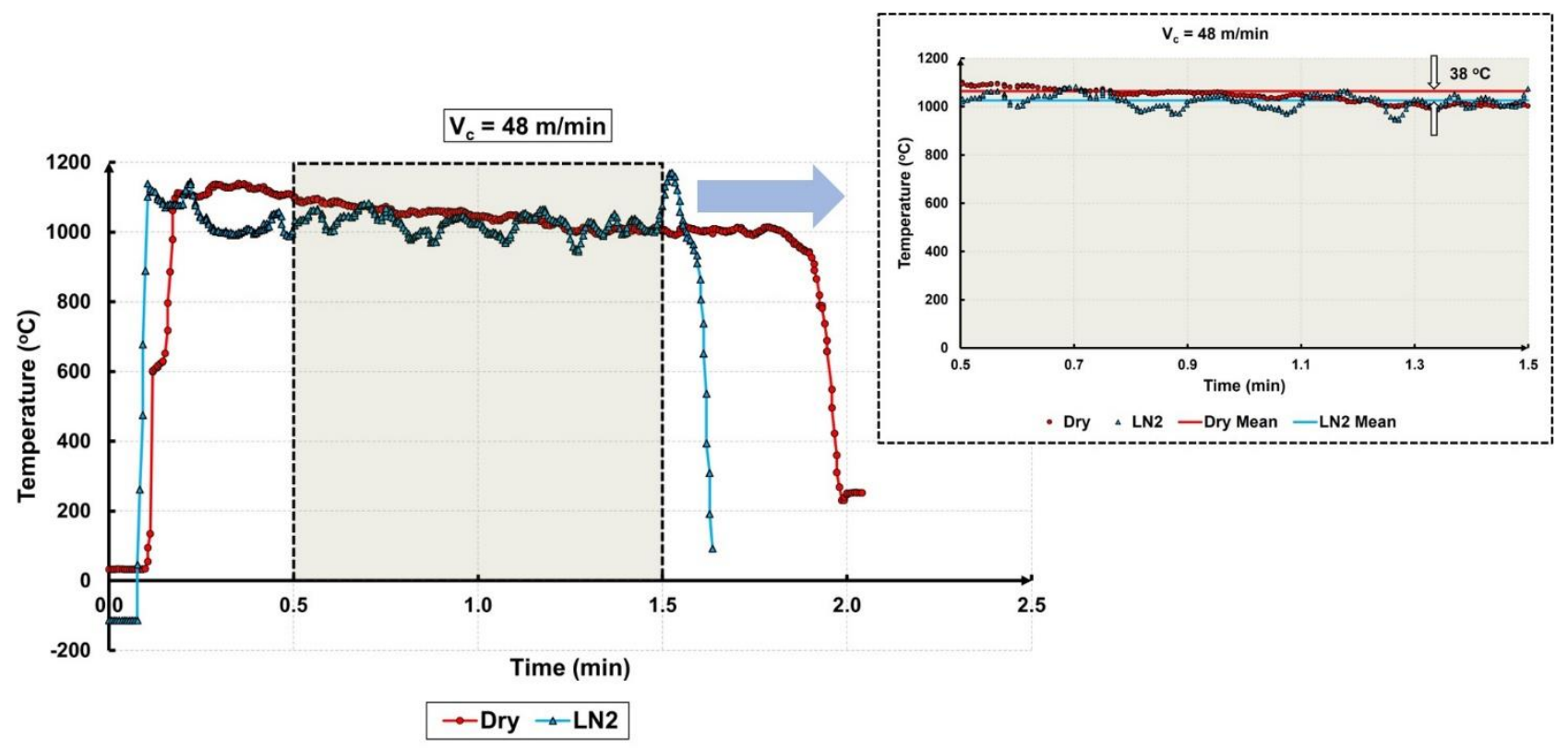

Figure 19. Chip-tool interface temperature vs time for the dry and $L N_{2}$ strategies at $V_{c}=48 \mathrm{~m} / \mathrm{min}$. 


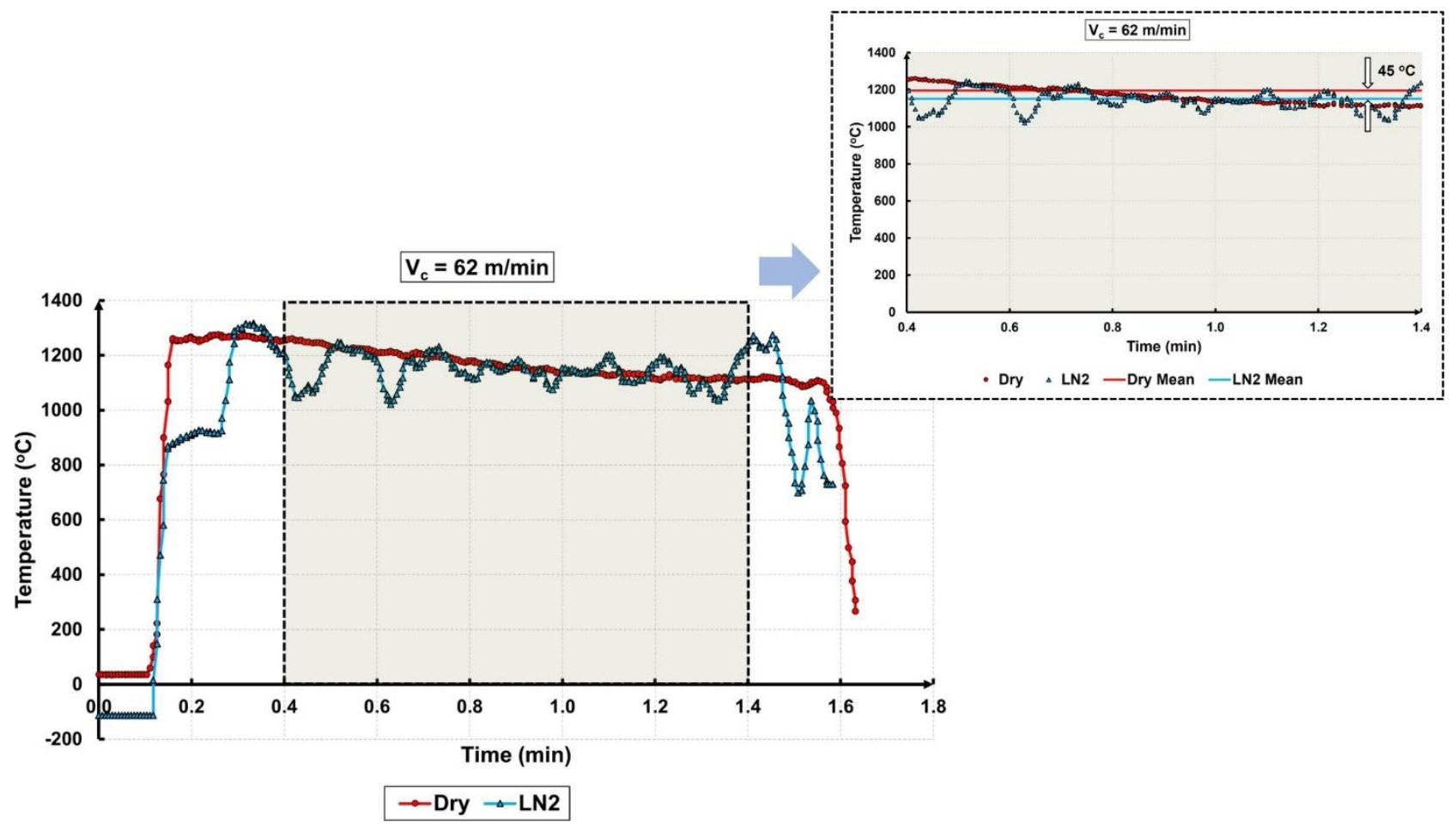

Figure 20. Chip-tool interface temperature vs time for the dry and $\mathrm{LN}_{2}$ strategies at $\mathrm{V}_{\mathrm{c}}=62 \mathrm{~m} / \mathrm{min}$.

With regard to the remark 1, a hypothesis raised is that this high signal oscillation behavior is due to the variation in the $\mathrm{LN}_{2}$ flow rate during the turning tests. It was observed that this variation sometimes occurred with a nearly constant frequency, as shown by the results in Fig. 20. This could be attributed to the corresponding oscillation in the copper tube position (Fig. 21), provoking an irregular flow of $\mathrm{LN}_{2}$ at the cutting zone.

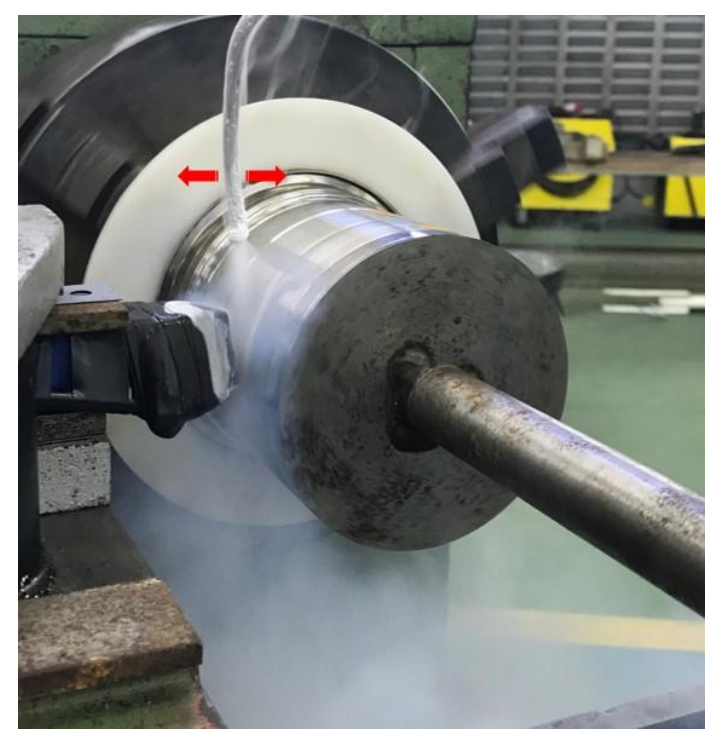

Figure 21. Oscillation of the copper tube during the turning tests. 
In relation to remark 2, an increase in the cutting temperature with the cutting speed is well documented in the field of machining. The tool-chip interface temperature increases with the cutting speed because additional energy is introduced into the process of chip formation, resulting in extra heat conversion and higher temperatures. Figure 22 shows the average tool-chip interface temperatures as a function of the cutting speed and cooling strategy. These average temperatures were obtained taking into account the values delimited by the insets in Figures 18 to 20, which were considered to represent the steady-state conditions. It is clear that the cutting temperature increases for both cutting strategies when the cutting speed is increased, but high cutting temperatures can be noted even when low cutting speeds were applied. In this case, it is important to emphasize that the temperatures reported were obtained from electrical signals generated in a small area of tool-chipworkpiece contact. In addition, the workpiece material used in this research was hardened tool steel with a hardness of $\sim 57 \mathrm{HRC}$, which was machined using an insert with an extremely negative microgeometry (rake angle of $-26^{\circ} \mathrm{C}$ ), i.e., conditions favorable for the development of high cutting temperatures. It is also important to remember that these temperatures were obtained considering a linear calibration curve and thus the values may have been overestimated.

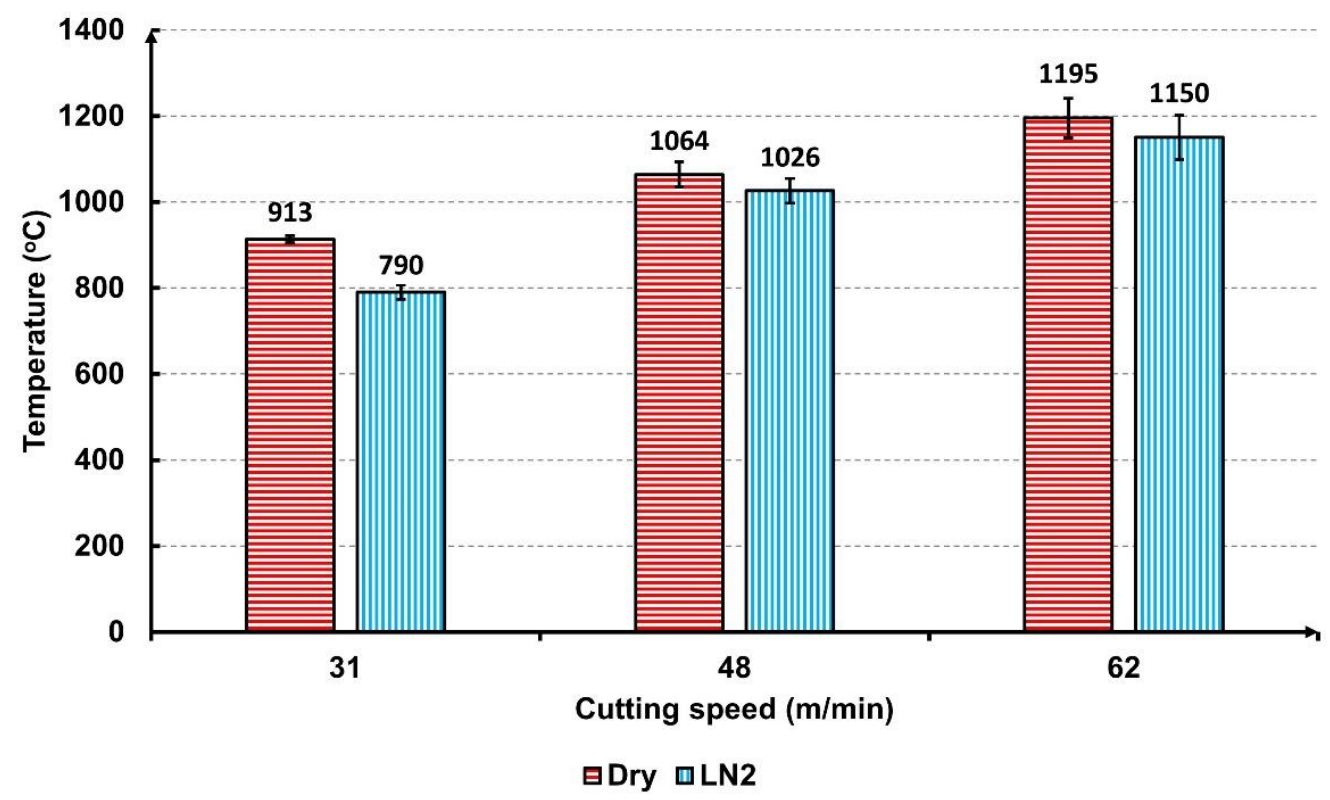

Figure 22. Tool-chip interface temperature as a function of cutting speed and cooling strategy.

Regarding remark 3 , it was noted that the $\mathrm{LN}_{2}$ strategy was able to reduce the average tool-chip interface temperature, mainly at the lower cutting speed $(31 \mathrm{~m} / \mathrm{min})$. In this case, a difference of 123 ${ }^{\circ} \mathrm{C}$ was considered. However, at higher cutting speeds the ability of the $\mathrm{LN}_{2}$ strategy to reduce the cutting temperature at the tool-chip interface diminished. The values for the cutting temperatures under dry and $\mathrm{LN}_{2}$ conditions were $38{ }^{\circ} \mathrm{C}$ and $45{ }^{\circ} \mathrm{C}$ for the cutting speeds of 48 and $62 \mathrm{~m} / \mathrm{min}$, respectively. This difference can have important implications in the case of extremely high temperatures $\left(1000^{\circ} \mathrm{C}-1200^{\circ} \mathrm{C}\right)$, particularly in terms of reducing the tool wear mechanisms, demonstrating that liquid nitrogen is also important at high cutting speeds. Nevertheless, it is important to remember that liquid nitrogen was delivered only at the flank face in this investigation, which would have influenced the results. The application of $\mathrm{LN}_{2}$ in the machining of hardened tool steels is 
therefore a good alternative for reducing the cutting temperature, without causing collateral effects on the environment, since this is a very eco-friendly system.

\section{CONCLUSIONS}

In this study, the tool-chip interface temperature during the turning of quenched and tempered AISI D6 tool steel was investigated under dry conditions and with liquid nitrogen delivered at the flank face of PCBN inserts. An experimental system was specially developed, based on the tool-workpiece thermocouple technique. From the results obtained, the following conclusions can be drawn:

- The tool-workpiece thermocouple method is extremely laborious and difficult to perform, but can be successfully used to measure the tool-chip interface temperature when turning hardened tool steels with the application of $\mathrm{LN}_{2}$.

- The tool-chip interface temperature increases with the cutting speed, regardless of the cooling conditions.

- For the three cutting speeds investigated, liquid nitrogen was able to reduce the tool-chip interface temperature (on average), but it was less effective at the highest cutting speed, although the effect is still important because it may reduce tool wear.

- The application of liquid nitrogen directly to the main flank face of the cutting tool caused considerable oscillation in the tool-chip interface temperature.

- The results of the application of $\mathrm{LN}_{2}$ in the turning of highly hardened steel is a good alternative for reducing the cutting temperature with no impact on the environment because this is an eco-friendly gas.

\section{ACKNOWLEDGEMENTS}

The authors would like to thank the following collaborators for their important contribution, without which this investigation could not have been performed: Professor Carlos Chesman for supplying the liquid nitrogen used in all steps of the study and the Brazilian government research agencies CNPq, and Coordenação de Aperfeiçoamento de Pessoal de Nível Superior - Brasil (CAPES) - Finance Code 001 for financial support.

\section{REFERENCES}

[1] Dosbaeva, GK, El Hakim, MA, Shalaby, MA, Krzanowsky, JE, Veldhuis, SC. Cutting temperature effect on PCBN and CVD coated carbide tools in hard turning of D2 tool steel. Int. Journal of Refractory Metals and Hard Materials 2015;50:1-8. https://doi.org/10.1016/j.ijrmhm.2014.11.001

[2] Sharma, R, Bansal, V, Nischal, C. Effect of cutting parameter on hard turning by using different lubricating conditions: A review. International Journal of Engineering Trends and Technology (IJETT) 2015;30(2):75-82. http://dx.doi.org/10.14445/22315381/IJETT-V30P215

[3] Hashimoto, F, Guo, YB, Warren, AW. Surface integrity difference between hard turned and ground surfaces and its impact on fatigue life. Ann. CIRP 2006;55(1):81-84.

https://doi.org/10.1016/S0007-8506(07)60371-0 
[4] Guo, YB, Yen, DW. Hard turning versus grinding - the effect of process-induced residual stress on rolling contact. Wear 2004;256:393-399. https://doi.org/10.1016/S0043-1648(03)004435

[5] Matsumoto, Y, Hashimoto, F, Lahoti, G. Surface integrity generated by precision hard turning. Annals of the CIRP 1999;48(1):59-62. https://doi.org/10.1016/S0007-8506(07)63131-X

[6] Benedicto, E, Carou, D, Rubio, EM. Technical, economic and environmental review of the lubrication/cooling system used in machining processes. Procedia Engineering 2017;184:99-116. https://doi.org/10.1016/j.proeng.2017.04.075

[7] Malek, J, Desai, TN. Prioritization of sustainable manufacturing barriers using Best Worst Method. Journal of Cleaner Production 2019;226:589-600.

https://doi.org/10.1016/j.jclepro.2019.04.056

[8] Del Re, F, Dix, M, Tagliaferri, F. Grinding burn on hardened steel: characterization of onset mechanisms by design of experiments. International Journal of Advanced Manufacturing Technology 2018;101:2889-2905. https://doi.org/10.1007/s00170-018-3156-6

[9] Leadebal Jr, WV, Melo, ACA, Oliveira, AJ, Castro, NA. Tool wear and chip analysis after the hard turning of AISI D6 steel assisted by $L_{2}$. Machining Science and Technology 2019;23(6): 886-905. https://doi.org/10.1080/10910344.2019.1636268

[10] Leadebal Jr, WV, Melo, ACA, Oliveira, AJ, Castro, NA. Effects of cryogenic cooling on the surface integrity in hard turning of AISI D6 steel. Journal of the Brazilian Society of Mechanical Sciences and Engineering 2018;40(1):1-14. https://doi.org/10.1007/s40430-017-0922-6

[11] Kaynak, Y, Lu, T, Jawahir, IS. Cryogenic machining-induced surface integrity: a review and comparison with dry, MQL, and flood-cooled machining. Machining Science and Technology: An International Journal 2014;18(2):149-198. https://doi.org/10.1080/10910344.2014.897836

[12] Shokrani, A, Dhokia, V, Muñoz-Escalona, P, Newman, ST. State-of-the-art cryogenic machining and processing. International Journal of Computer Integrated Manufacturing 2013;26(7):616-648. https://doi.org/10.1080/0951192X.2012.749531

[13] Biček, M, Dumont, F, Courbon, C, Pušavec, F, Rech, J, Kopač, J. Cryogenic machining as an alternative turning process of normalized and hardened AISI 52100 bearing steel. Journal of Materials Processing Technology 2012;212:2609-2618.

https://doi.org/10.1016/j.jmatprotec.2012.07.022

[14] Hong, SY, Ding, Y, Jeong, J. Experimental evaluation of friction coefficient and liquid nitrogen lubrication effect in cryogenic machining. Machining Science and Technology 2002;6(2):235-250. http://dx.doi.org/10.1081/MST-120005958

[15] Hong, SY, Ding, Y. Cooling approaches and cutting temperatures in cryogenic machining of Ti-6Al-4V. International Journal of Machine Tools \& Manufacturing 2001;41:1417-1437. https://doi.org/10.1016/S0890-6955(01)00026-8

[16] Dhar, NR, Paul, S, Chattopadhyay, AB. Role of cryogenic cooling on cutting temperature in turning steel. Transactions of the ASME 2002;124:146-154. https://doi.org/10.1115/1.1413774

[17] Kaminise, AK, Guimarães, G, da Silva, MB. Development of a tool-work thermocouple calibration system with physical compensation to study the influence of tool-holder material on cutting temperature in machining. International Journal of Advanced Manufacturing and Technology 2014;73:735-747. https://doi.org/10.1007/s00170-014-5898-0 
[18] Shaw, MC. Metal Cutting Principles. 2nd ed., Oxford NY: Oxford University Press; 2005.

[19] Santos Jr, MC, Machado, AR, Barrozo, MAS, Martins Neto, L, Coelho, EAA. Influence of Thermoelectric Junctions on the Electrical Signals Generated by the Tool-Workpiece Thermocouple System in Machining. Measurement 2013;46:2540-2546.

https://doi.org/10.1016/j.measurement.2013.04.056

[20] Santos Jr, MC, Araújo Filho, JS, Barrozo, MAS, Jackson, MJ, Machado, AR. Development and application of a temperature measurement device using the tool-workpiece thermocouple method in turning at high cutting speeds. The International Journal of Advanced Manufacturing Technology 2017;89(5):2287-2298. https://doi.org/10.1007/s00170-016-9281-1

[21] Stephenson, DA. Tool-work thermocouple temperature measurements: Theory and Implementation Issues. Transactions of the ASME 1993;115(4):432-437.

https://doi.org/10.1115/1.2901786

[22] Fernandes, MEP, Melo, ACA, Oliveira, AJ, Chesman, C. Hard turning of AISI D6 tool steel under dry, wet and cryogenic conditions: An economic investigation aimed at achieving a sustainable machining approach. Cleaner Engineering and Technology 2020;1:100022. https://doi.org/10.1016/j.clet.2020.100022 


\section{DECLARATIONS}

\section{Funding}

The authors declare this work was funded by the Brazilian government research agencies CNPq, and Coordenação de Aperfeiçoamento de Pessoal de Nível Superior - Brasil (CAPES) - Finance Code 001 for financial support.

\section{Conflicts of interest/Competing interests}

The authors declare that they have no known competing financial interests or personal relationships that could have appeared to influence the work reported in this paper.

\section{Availability of data and material}

It is not available.

\section{Code availability}

It is not available.

\section{Author's contributions}

The authors declare the following on this section:

Edmilson Dantas de Lima Júnior was responsible for the experiments, methods, literature review, result discussion, conclusions, and for the first version of the manuscript in Portuguese.

Anderson Clayton Alves de Melo was responsible for the experiments, methods, result discussion, conclusions, and for translate the first version of the manuscript to English.

Adilson José de Oliveira was responsible for the result discussion, conclusions, and for revising the first version of the manuscript in English.

Júlio César Giubilei Milan was responsible for the result discussion, conclusions, and for revising the first version of the manuscript in English.

Álisson Rocha Machado was responsible for technically revising all the manuscript and English. 